\title{
Solid Phase Microextraction for the Analysis of Nuclear Weapons
}

Enhanced Surveillance Program Project \#13A

Jirne 1, 2001

Revision ?

David M. Chambers, Ph.D. 


\section{DISCLAIMER}

This document was prepared as an account of work sponsored by an agency of the United States Government. Neither the United States Government nor the University of California nor any of their employees, makes any warranty, express or implied, or assumes any legal liability or responsibility for the accuracy, completeness, or usefulness of any information, apparatus, product, or process disclosed, or represents that its use would not infringe privately owned rights. Reference herein to any specific commercial product, process, or service by trade name, trademark, manufacturer, or otherwise, does not necessarily constitute or imply its endorsement, recommendation, or favoring by the United States Government or the University of California. The views and opinions of authors expressed herein do not necessarily state or reflect those of the United States Government or the University of California, and shall not be used for advertising or product endorsement purposes. 


\section{Table of Contents}

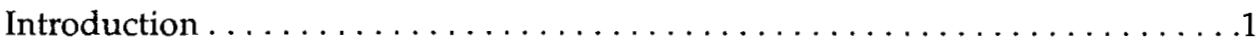

Solid Phase Microextraction in the Analysis of Nuclear Weapons . . . . . . . . 3

Why look for organic materials in a weapon headspace? $\ldots \ldots \ldots \ldots . . \ldots$

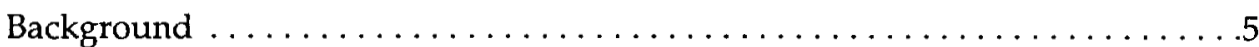

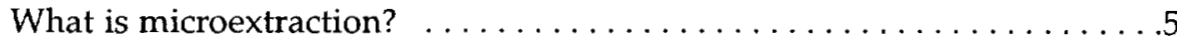

What other static headspace methods are available that might

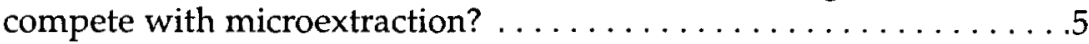

What makes microextraction different from other sample-collection approaches? . . . . . . . . . . . . . . . . . . . . . 5

How should analysis of microextraction fibers be approached? . . . . . .6

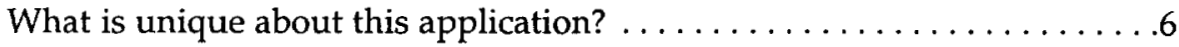

What are the advantages of using microextraction for the analysis of weapons and weapon materials? $\ldots \ldots \ldots \ldots \ldots \ldots \ldots \ldots$

What types of collection should be performed by microextraction? . . . . .6

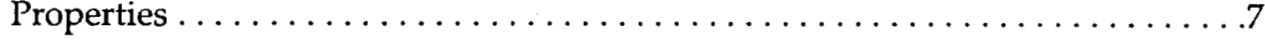

What are the attributes of the different fiber coatings that are available? .7

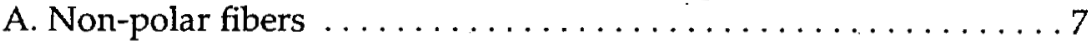

B. "Polar fibers" . . . . . . . . . . . . . . . . . . . . 10

C. "Bipolar fibers". ........................... 11

What factors affect sample-collection efficiency? ..............11

What properties affect accuracy and precision? ............... 12

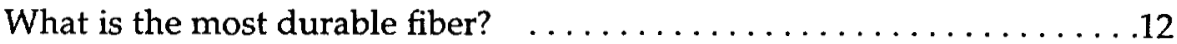

How reproducible can collection and analysis be? ..............13

What is the long-term reproducibility and lifetime benchmark for the fibers? . . . . . . . . . . . . . . . . . . . . . 14

What kind of lot-to-lot reproducibility can be achieved? . . . . . . . . . 14

Is there any competition between species that will interfere with quantification? ...........................

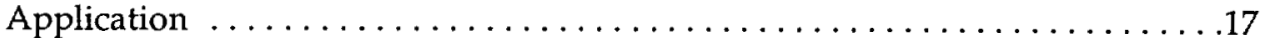

What is the most practical approach to quantify a sample of weapon

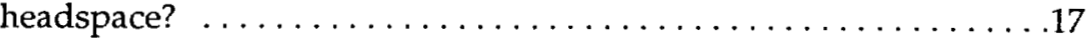

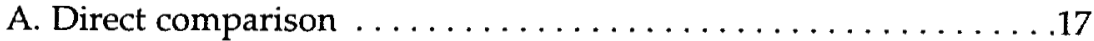

B. Discontinuous extraction ....................

How do we know we are using the right fiber? .............. 18

What is the right coating thickness? ..................... 19

What is the recommended collection time? .................. 19

What are the collection constraints for performing microextraction analysis on weapons? . . . . . . . . . . . . 19

How long can the samples be stored after collection? ...........20

What are currently the major application limitations $\ldots \ldots \ldots \ldots \ldots .22$

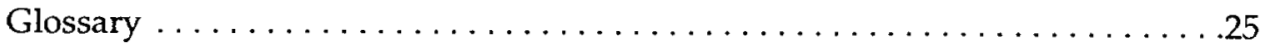

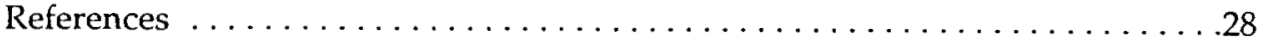


Jolid Phase Microextracrion for the Analysis of Nuclear Weapons 


\section{List of Figures and Tables}

Figure 1. Microextraction of LX-17 material taken from W84 PCS and

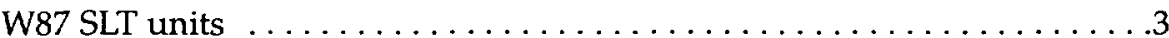

Figure 2. Comparison of a B83 Core B compatibility test unit and B83

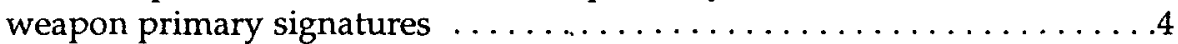

Figure 3. Design of the commercial SPME device made by Supelco $\ldots \ldots \ldots 5$

Figure 4. Relative response achieved with different polymer fiber coatings by gas phase collection of TNT over a 200-mg TNT equilibrium

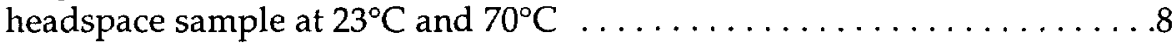

Figure 5. Increase in collection of 2,4-DNT and TNT upon heating the fiber assembly for the $100-\mu \mathrm{m}$ PDMS coated fiber $\ldots \ldots \ldots \ldots \ldots \ldots$.

Figure 6. $1.9 \mathrm{ppm}$ toluene standard collected with a 100- $\mu \mathrm{m}$ PDMS-coated

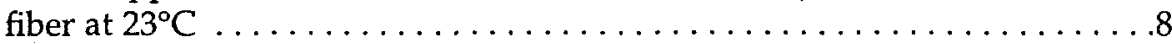

Figure 7. $1.9 \mathrm{ppm}$ toluene standard collected with a 75- $\mu \mathrm{m}$ Carboxen-coated

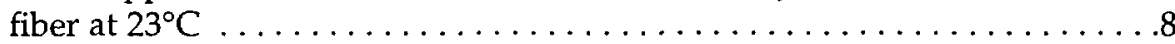

Figure 8. Scanning electron micrographs of fiber surface for (a) PDMS, (b) PA, (c) CW/DVB, (d) PDMS/ DVB, and (e) Carboxen/PDMS coatings at a magnification of $5000 \ldots \ldots \ldots \ldots \ldots \ldots \ldots$

Figure 9. Scanning electron micrographs of fiber cross sections for (a) PDMS, (b) PA, (c) CW/DVB, (d) PDMS/DVB, (e) Carboxen/PDMS, and

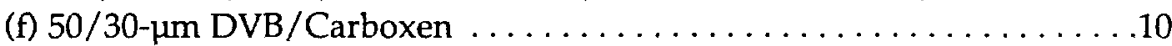

Figure 10. Response for a 1.9-ppm toluene standard collected for $15 \mathrm{~min}$ following immediate desorption cleaning and after being left unprotected for approximately $18 \mathrm{hr}$ under ambient conditions

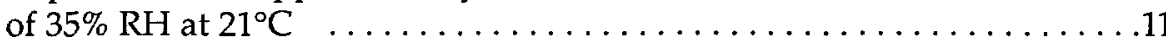

Figure 11. Comparison of polysulfide material signature collected with 100- $\mu \mathrm{m}$ PDMS and 75- $\mu \mathrm{m}$ Carboxen-coated fibers exposed $20 \mathrm{~min}$ at an equilibrium temperature of $21^{\circ} \mathrm{C} \ldots \ldots \ldots \ldots \ldots \ldots \ldots \ldots \ldots \ldots \ldots \ldots \ldots \ldots \ldots$

Figure 12. Scanning electron micrograph of PDMS/DVB surface showing fracturing of the coating. This type of fracturing is reduced in the newest lots, which appear to have greater amounts of PDMS adhesive ..13

Figure 13. Scanning electron micrograph of Carboxen fiber cross section $\ldots .13$

Figure 14. Equilibration collection of a 1-ppm toluene air standard using a

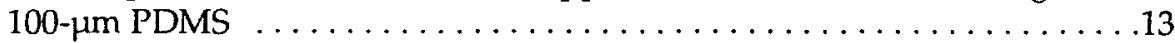

Figure 15. Comparison of response representing (1) reactive, (2) and (3) volatile low surface activity, and (4) semivolatile high surface activity compounds for different lots of 100-pm PDMS coated fibers . . . 14

Figure 16. Response for compound mixture at different dilutions for a 5-min collection at $23^{\circ} \mathrm{C}$ with a $100-\mu \mathrm{m}$ PDMS coated fiber . . . . . . . . . 15

Figure 17. Toluene collected from a 10-mg LX-17-1 equilibrium headspace

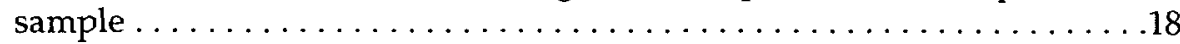


Figure 18. Comparison of 200-mg equilibrium headspace samples of TNT under standard conditions (i.e., $23^{\circ} \mathrm{C}, 35 \% \mathrm{RH}$ ) as a function of time for different thicknesses of the PDMS coating . ....................... 19

Figure 19. Comparison of B83 primary headspace signatures collected at different locations downstream from the weapon purge valve . . . . . . 20

Figure 20. Loss of toluene from a 100- $\mu \mathrm{m}$ PDMS-coated fiber that was left

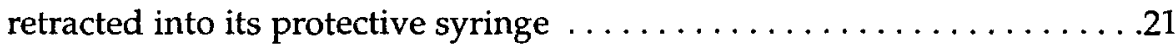

Figure 21. Effect of long-term storage on response for 100- $\mu \mathrm{m}$ PDMS-coated fiber sealed in the syringe with a Teflon cap $\ldots \ldots \ldots \ldots \ldots \ldots \ldots .21$

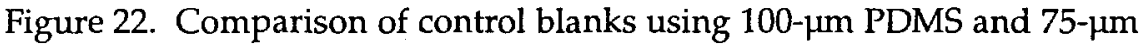
Carboxen-coated fibers taken off the gas bottle rack manifold at the Mason \& Hanger Pantex Plant . . . . . . . . . . . . . . . . . 22

Figure 23. Comparison of microextraction analysis representing (a) an instrument and fiber blank, (b) a process control blank of the gas sampling --manifold, and (c) of the weapon headspace $\ldots \ldots \ldots \ldots \ldots \ldots \ldots .23$

Table I. Estimated glass transition temperatures and thermogravimetric analysis procedural decomposition temperatures for available

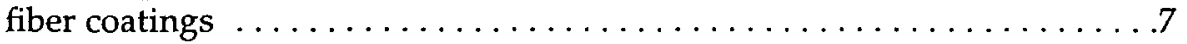




\section{Introduction}

This document is a compendium of answers to commonly asked questions about solid phase microextraction as it relates to the analysis of nuclear weapons. We have also included a glossary of terms associated with this analytical method as well as pertinent weapons engineering terminology.

Microextraction is a new collection technique being developed to nonintrusively sample chemicals from weapon headspace gases for subsequent analysis. The chemicals that are being targeted outgas from the high explosives and other organic materials used in the weapon assembly. This technique is therefore a valuable tool to: (1) remotely detect and assess the aging of Lawrence Livermore National Laboratory (LLNL) and, in some cases, Sandia National Laboratory (SNL) organic materials; and (2) identify potential compatibility issues (i.e., materials interactions) that should be more carefully monitored during surveillance teardowns.

Microextraction is particularly attractive because of the practical constraints inherent to the weapon surveillance procedure. To remain transparent to other core surveillance activities and fall within nuclear safety guidelines, headspace analysis of the weapons requires a procedure that: (1) maintains ambient temperature conditions; (2) allows practical collection times of less than $20 \mathrm{~min}$; (3) maintains the integrity of the weapon gas volume; 4) provides reproducible and quantitative results; and (5) can identify all possible targets. 
Solid Phase Microextraction for the Analysis of Nuclear Weapons 


\section{Solid Phase Microextraction in the Analysis of Nuclear Weapons}

\section{Why look for organic materials in a weapon headspace?}

Many of the organic materials used in weapons are amorphous and semicrystalline polymers that are generally thought to be chemically stable and have characteristically small bulk diffusion coefficients for volatiles $\left(10^{-11}\right.$ to $\left.10^{-5} \mathrm{~cm}^{2} / \mathrm{s}\right)$. However, we have determined that within the various weapon compartments these materials can outgas at significant levels mainly because they remain hermetically sealed for many years, experience temperatures at or above the material's glass transition $\left(\mathrm{T}_{\mathrm{g}}\right)$, and are exposed to radiation. The chemicals that are outgassing can include: (1) synthesis precursors, aids, and by-products; (2) formulation and manufacturing ingredients; and (3) degradation products. In addition to detecting changes in materials from aging, microextraction can be used to detect other "defects," such as an incompletely cured adhesive or organic residues left over from the assembly or rebuild of weapon components. One example would be the new environmentally friendly cleaning solvents that are difficult to remove, yet must be used in the manufacture of today's electronic packages.
The first phase of this project involves identifying what chemicals are emitted by the different weapon components and relating these signatures to those found in the weapon headspace itself. So far we have characterized materials associated with the W87 and B83 weapons and have analyzed high explosives from two W87 weapons. The results shown in Fig. 1 compare total ion chromatograms of signatures from the high explosive (LX-17) taken from cycle 9 and 10 W87 nuclear weapons, with those from two W84 aging/compatibility core test units. One of the W84 core test units was thermally cycled (experiencing a total of $4464 \mathrm{hr}$ at $71^{\circ} \mathrm{C}$ over an 8-yr period) and the other was stored under ambient laboratory conditions for 8 years. The W84 aging/compatibility core test units were selected for this comparison because they have materials similar to those found in the W87 weapons and for this reason have been combined with the W87 program.' Some of the additional compounds absorbed in the LX-17, such as the aldehydes, alkanes and silicone, can be traced back to other materials in the weapon package. The remaining compounds are believed to be synthesis byproducts of 1,3,5-triamino-2,4,6-trinitrobenzene (TATB), which is the high explosive used in the LX-17

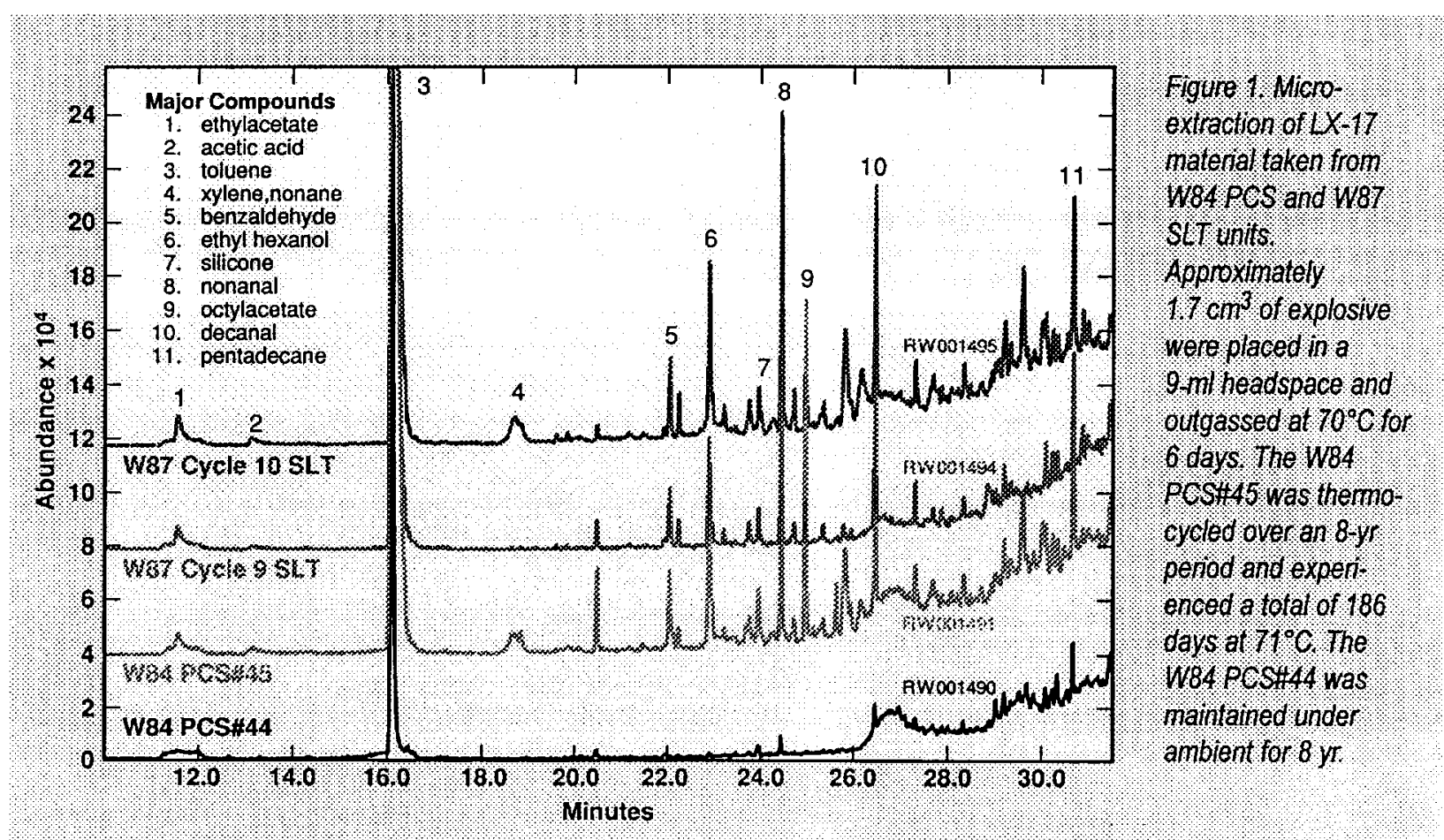


formulation. The most significant of these by-products is toluene, which is used as a solvent for the $1,3,5-$ trichloro-2,4,6-trinitrobenzene precursor in the synthesis of TATB. We believe that higher levels of toluene and other chemicals from the "aged" LX-17 occur because the crystalline structure of the TATB is being stressed and is thus better able to liberate trapped compounds.

The second and most recent application of this technique involves the analysis of different weapon systems. At this time we have included microextraction analysis (along with the routine, nondestructive surveillance performed at Mason \& Hanger Pantex Plant) of B83 primaries, W87 primaries, and aging/compatibility test units from the W68, B83, and W84 programs. The W68 and W84 compatibility test units are relevant because they use materials found in LLNL's enduring stockpile weapons. Weapon and thermally cycled aging/compatibility test unit signatures for the B83 systems are strikingly similar as shown in Fig. 2. These results demonstrate the similarity between stockpile weapons and thermally cycled aging/compatibility test units on a chemical level. This is, to our knowledge, the first time the design intent of the compatibility test has been validated to this level of chemical detail.

Our objective is to complete the initial survey of LLNL weapons, compatibility test units, and associated materials that make up the enduring stockpile. This work will include LLNL designed canned subassemblies (CSA) subjected to destructive evaluation at the Lockheed Martin Y-12 plant. From this work we will be able to: (1) provide a description of the weapon gas environment and how this changes with aging; and (2) identify specific chemical compounds that will serve as indicators for undesirable material interactions (i.e., incompatibility). This information can be used by modelers, material specialists, and engineers to help predict or diagnose aging, contamination, and possibly failure of materials or parts.

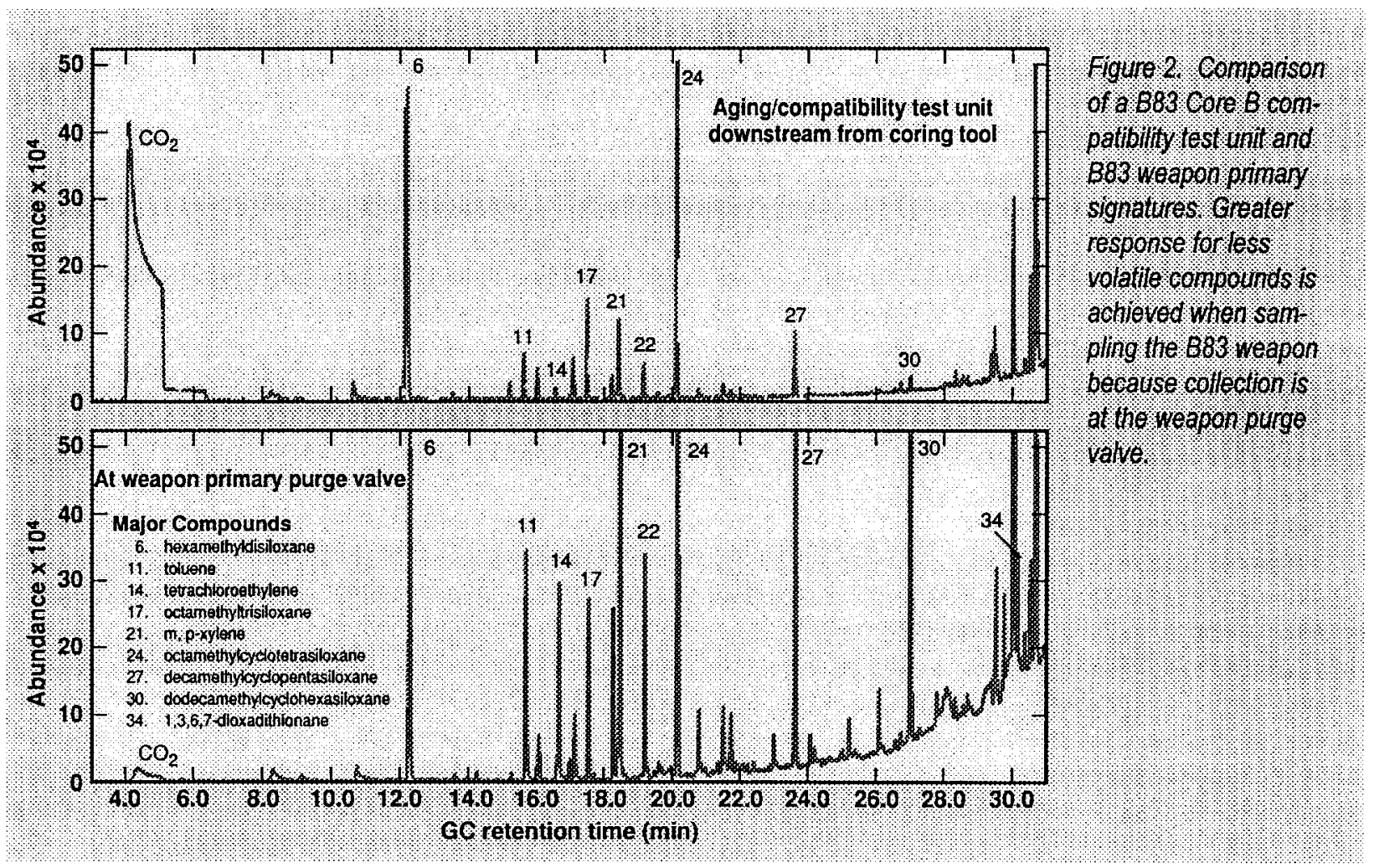




\section{Background}

\section{What is microextraction?}

Solid phase microextraction (SPME) is a new sampling technique for the collection of trace chemicals from liquids, solids, and gases. ${ }^{2}$ The first commercial SPME device, which is shown in Fig. 3, was introduced by Supelco Inc. in 1993. The active part of the device uses a 100- $\mu \mathrm{m}$-diameter fused-silica fiber coated with an appropriate absorbent that can be used to accumulate dissolved chemicals in liquids, volatiles in gases, and outgassed chemicals from solids with little perturbation of the sample.

\section{What other static headspace methods are available that might compete with microextraction?}

Techniques available for monitoring species in the gas phase can be differentiated as optical and non-spectro-

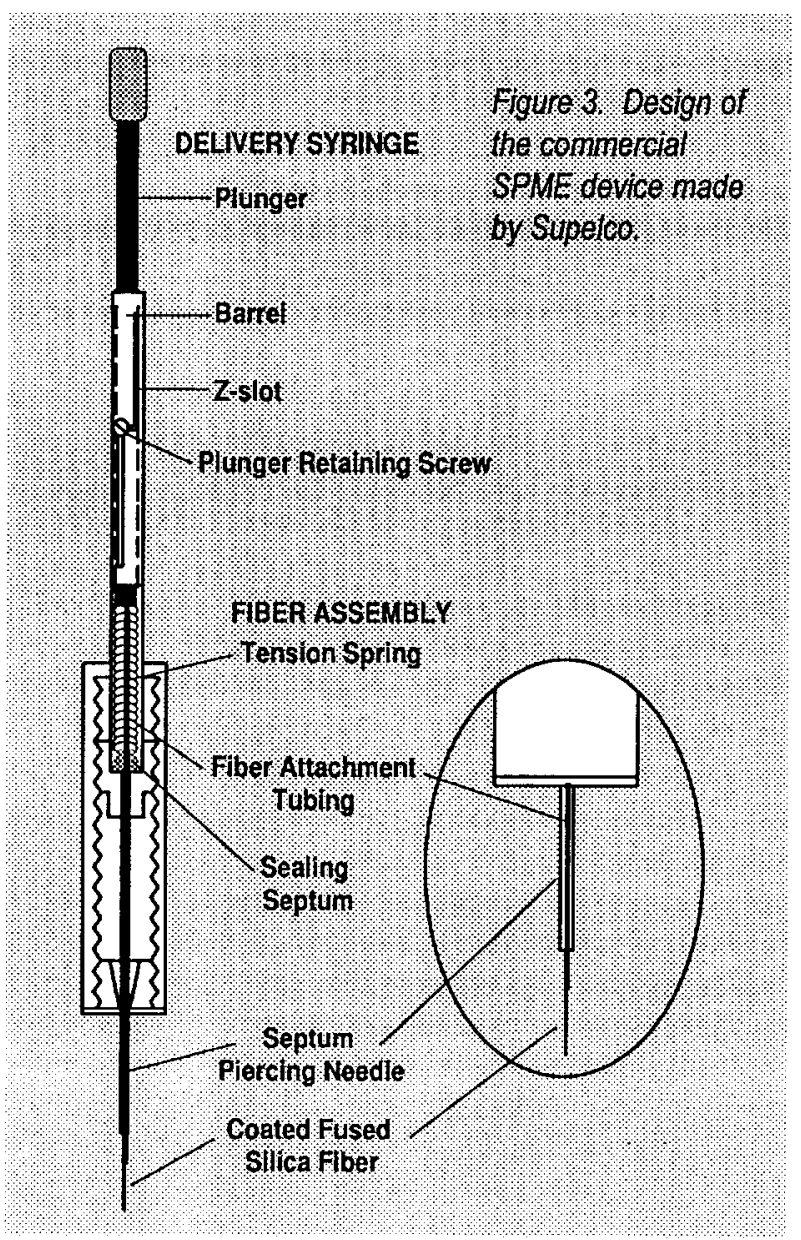

scopic. Optical techniques either interrogate specific compound vibrations and rotations or probe the molecular structure by exciting multiple vibrations and rotations. Although optical techniques are well suited for static headspace analysis because they do not consume the gas matrix or analyte, they lack both the sensitivity and specificity needed to identify large molecules at trace levels as they exist in a complex matrix. For this reason, the most common methods for monitoring chemicals in a gaseous environment involve dynamic collection into containers (e.g., plastic bags, glass or metal canisters) or by solid sorbent traps (e.g., Tenax, silica gel, or activated charcoal) followed by gas chromatographic (GC) separation and mass spectrometry (MS) analysis. ${ }^{3}$ Although these approaches can provide sufficient sensitivity ${ }^{4-8}$ and specificity, a large gas volume is required. A number of direct mass spectrometric techniques involving membrane 9,10 and direct introduction $^{11-17}$ can achieve detection in the low- to sub-partper-billion ( $\mathrm{ppb}$ ) range and consume very little gas; however, these approaches are less amenable to the analysis of high molecular-weight or polar compounds, which are readily lost at the inlet interface from their high-surface activity. In this application high-sensitivity detection of large compounds is important because these are often by-products of polymer degradation.

\section{What makes microextraction different from other sample-collection approaches?}

The true advantage of this technique is that the small size of the microextraction fiber, which is typically $<300 \mu \mathrm{m}$ in diameter and $1 \mathrm{~cm}$ in length, permits highly efficient delivery for GC analysis. The fiber is generally retracted within a 24-gauge septum-piercing sheath needle and can be inserted and exposed directly within the heated injection port of the GC. Compounds collected in the fiber absorbent are delivered directly to the tip of the GC column with little loss or dilution. If GC separation is used in conjunction with MS analysis, which provides molecular weight and structural information for a broad range of compounds, detection limits are routinely in the low- and sub-ppb range, even for polar species. 


\section{How should analysis of microextraction fibers be approached?}

For this application, analysis will be performed by $\mathrm{GC} / \mathrm{MS}$, whereby the fiber is thermally desorbed between 200 and $250^{\circ} \mathrm{C}$ in the injection port under an inert helium environment. The standard GC injection port is configured to accommodate 1 - to 5 - $\mu$ l liquid injections by using a large volume injection port liner and splitting only a small portion of the sample to the $\mathrm{GC}$ column. This large volume and splitting are not necessary for microextraction analysis, which is a microcollection method. ${ }^{18,19}$ The greatest response and narrowest injection band can be achieved with a narrow bore (i.e., $0.75-\mathrm{mm}$ ) injection port liner and by not splitting the sample at the injection port.

\section{What is unique about this application?}

Although microextraction collection is most commonly performed in or over an aqueous phase, ${ }^{20-22}$ we have found it to be particularly well suited for collecting gaseous polymer by-products over a solid phase. The advantages of working in the gas phase are that: (1) permanent gases such as nitrogen, oxygen, carbon dioxide, and water are not readily concentrated in the fiber; (2) the fiber coatings are not affected by the solid phase, whereas in a liquid phase extraction, the matrix can significantly alter the absorbent characteristics of the fiber coating (i.e., polarity, $T_{g}$, and swelling) ${ }^{23}$; and (3) the coatings remain relatively unaffected by changes in ambient conditions such as extremely high humidity ${ }^{24}$ This is particularly true for the polydimethylsiloxane (PDMS) coating, which is a relatively non-polar medium that remains nearly unaffected at a humidity of up to $100 \%$.

Also, in the gas phase there is no concern about analyte depletion at the fiber/gas interface because of the high diffusion rate in the gas phase with diffusion coefficients that are typically on the order of $0.1 \mathrm{~cm}^{2} / \mathrm{s}$. Equilibration is limited only by diffusion into the fiber coating. In aqueous solutions, especially if the partition coefficient is large, a thin analyte depletion layer of water forms that surrounds the fiber. Diffusion of analyte through this boundary layer is the rate-limiting step and slows equilibration. Quite often, this layer is difficult to eliminate even with vigorous stirring.

\section{What are the advantages of using microextraction for the analysis of weapons and weapon materials?}

Typical fibers are up to $300 \mu \mathrm{m}$ in diameter and approximately $1 \mathrm{~cm}$ in length so sample collection, which is in the nanogram range, does not interfere with the weapon headspace either by depletion or contamination. The gas volume collected from the weapon is limited to the dead volume of the microextraction collection vessel that holds the fiber assembly. The dead volume of the current design is $2.5 \mathrm{ml}$. Because microextraction collection is a passive sampling approach requiring no external energy, a nuclear explosives safety study (NESS) is not needed. This technique has already been evaluated by the Nuclear Safety Department at the BWXT Pantex Plant for use on nuclear weapons and the microextraction tool does not require electrical isolation. This technique is readily implemented at Pantex because it is safe, does not interfere appreciably with current core surveillance, and provides detection and identification for a broad range of chemicals in the weapon headspace.

Following sample collection, the fiber can be analyzed immediately by a field portable GC/MS or hermetically sealed in the sheath needle and transported back to a laboratory for analysis by GC/MS. At Pantex the microextraction collectors are sealed and transported back to the Gas Analysis Laboratory to be analyzed. We are able to identify unknown compounds as they exist in a complex mixture at low- to sub-ppb levels.

\section{What types of collection should be per- formed by microextraction?}

Microextraction is a microcollection technique that is well suited for compounds that are not highly volatile, and when detection in the ppb to part-per-trillion (ppt) range is required. This would include compounds that have high surface activity (i.e., are sticky) and are difficult to collect and transfer to an instrument for analysis. Also, a particular application scenario may require its use (e.g., the need for remote sampling)

In most applications, compounds that are gases under standard conditions (e.g., < C6, permanent gases, fluorocarbons) and have concentrations in the part-per-million (ppm) range are more easily collected and quantified by analyzing a few milliliters of the bulk gas. Therefore, microextraction should be thought of as a complement to gas bottle analysis, which is already part of core surveillance. 


\section{Properties}

\section{What are the attributes of the different fiber coatings that are available?}

Those material characteristics that significantly influence the fiber adsorption equilibrium time, partition distribution, and desorption rate include material polarity, $\mathrm{T}_{\mathbf{g}}$, and effective surface area. The commercially available fibers are listed in Table I along with predicted $\mathrm{T}_{\mathrm{g}}$ and procedural decomposition temperatures $\left(\mathrm{T}_{\mathrm{i}}\right)$ obtained by thermogravametric analysis.

\section{A. Non-polar fibers (7-, 30-, and 100-um Polydi- methylsiloxane)}

The PDMS coating is available in three thicknesses7,30 and $100 \mu \mathrm{m}$. This coating is a moderately nonpolar phase with an extremely low $\mathrm{T}_{\mathrm{g}}$ (from -130 to $-120^{\circ} \mathrm{C}$ ), yet with high thermal stability. As a result, this coating is currently considered to be the most universal and robust of the available coatings.

The low $\mathrm{T}_{\mathrm{g}}$ indicates a high free-volume mobility, permitting diffusion of low-volatility polar compounds that would otherwise be better collected with more polar fiber coatings. Free-volume mobility relies on thermal motion of the polymer segments to create the movement of vacant spaces through which a penetrant can diffuse.

The advantage of high mobility over affinity is demonstrated in Fig. 4, which compares collection efficiency for the different coatings for gas-phase trinitrotoluene (TNT) at two different temperatures of $23^{\circ} \mathrm{C}$ and $70^{\circ} \mathrm{C}$. The $70^{\circ} \mathrm{C}$ response data has been attenuated by a factor of 10. At elevated temperatures the more polar coatings with higher affinity for TNT have the highest collection efficiency. For this reason, it is generally reported that these coatings are best suited for the collection of gas phase high explosives. ${ }^{25}$ However, at lower temperatures and short equilibration times such as those that will be encountered for weapon analysis, the PDMS coatings can be more efficient, particularly at even lower temperatures. Allowing for the difference in coating thickness, the more polar substrates (e.g., polyacrylate (PA), which have a $T_{g}$ near $100^{\circ} \mathrm{C}$, yields a lower response despite a greater affinity for TNT than the PDMS coating.

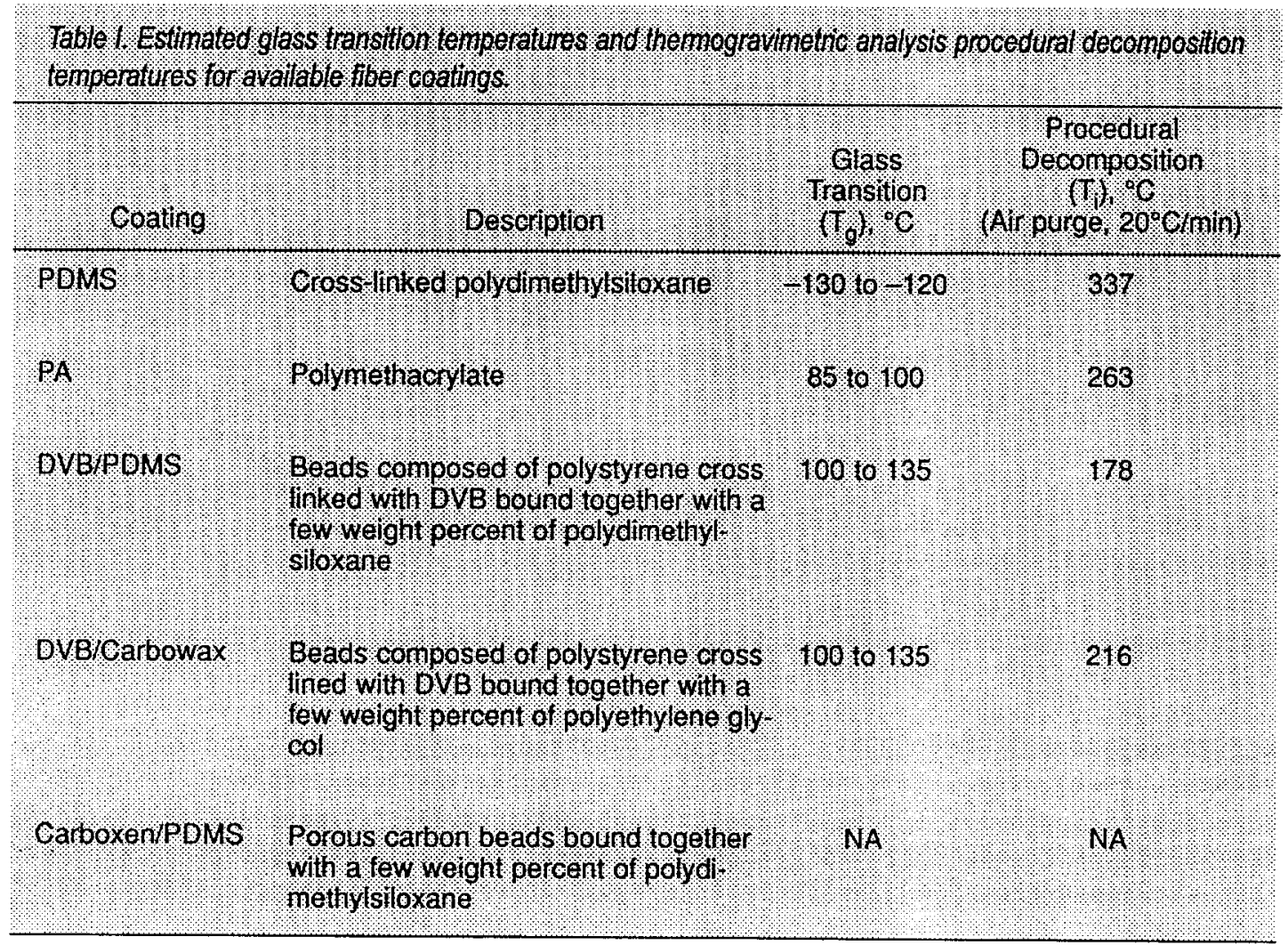


Only a modest improvement in efficiency is achieved by elevating the fiber temperature when already above its $\mathrm{Tg}$ as demonstrated by the Fig. 5 results for the 100mm PDMS coating. In this experiment, a 200-mg TNT equilibrium headspace sample at $23^{\circ} \mathrm{C}$ was collected for $20 \mathrm{~min}$ while heating the sheath needle. The control shown in Fig. 5 accounts for slight heating of the headspace by the sheath needle.

When compared with other fiber coatings, especially Carboxen, the PDMS coating has a relatively weak affinity for non-polar organic compounds. This becomes apparent when comparing the absorption and desorption rates as shown in Fig. 6 and 7. The equilibration rate for toluene absorption and desorption both yield a diffusion coefficient of approximately $2.5 \times 10-6$ $\mathrm{cm} 2 / \mathrm{s}$, while there exists a substantial difference between absorption and desorption for the Carboxen coating. The disparity demonstrates a different rate controlling process, which is expected because Carboxen is a solid-phase absorbent where diffusion occurs primarily through the adhesive between the particles.

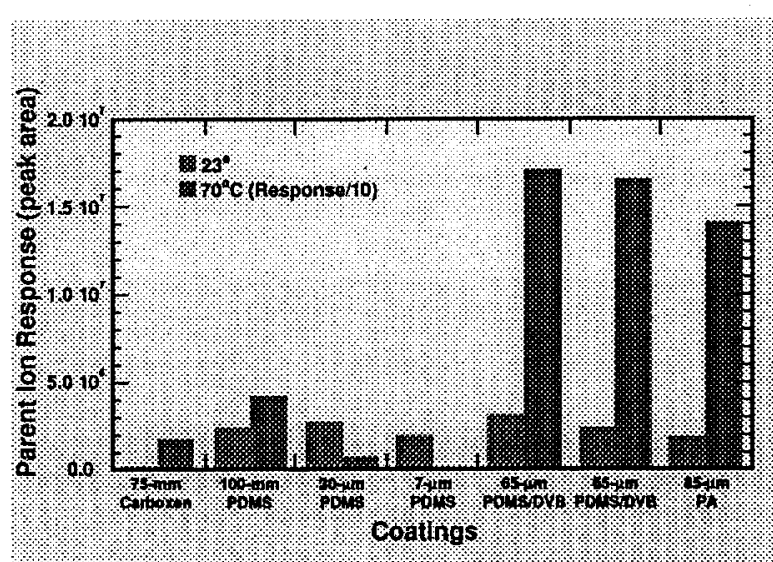

Figutre 4 . Relatwe resportse achileved with cilterent? polymer fiber coatings by gas phase collection of TWT over a $200 \mathrm{mg}$ TWT equilbriun headspace sample at $23^{\circ} \mathrm{C}$

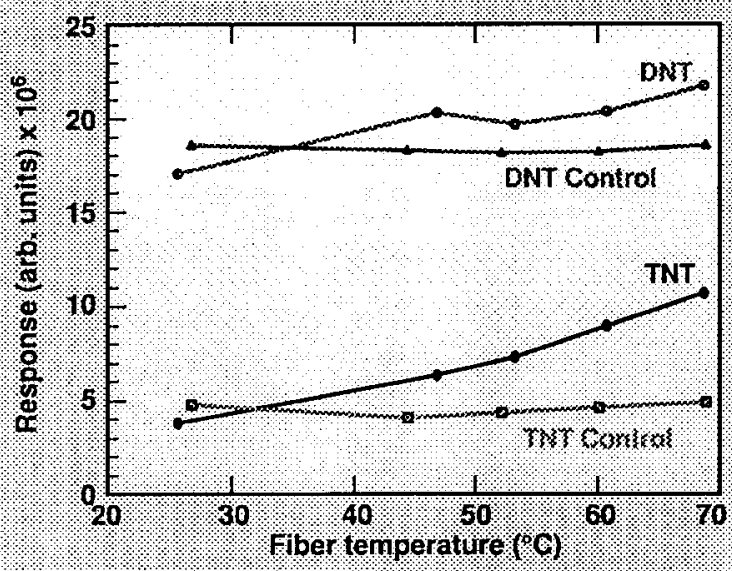

Figure 5 . Increase in collection or 2.4 - BNT and TNT upon heating the tiber assembly for the 100.4m PDMS coated fiber. The 22 and $36 \%$ increase, respectively. are attributed to faster equilibration given a fixed. cellection time of $20 \mathrm{~min}$

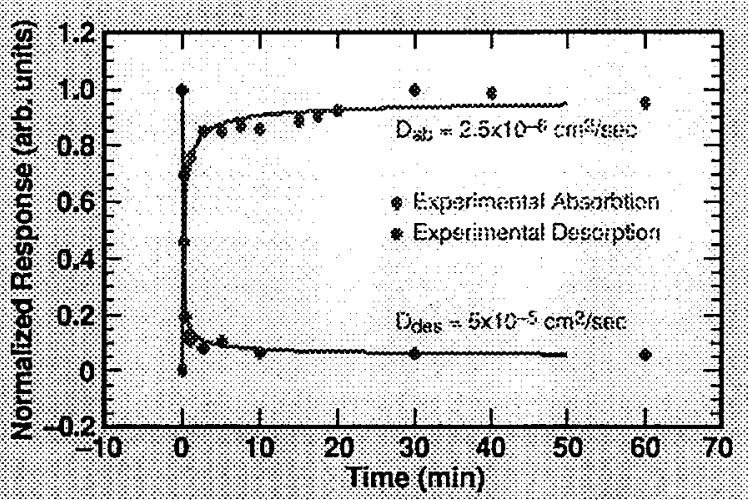

Figutre 6. $19.00 \mathrm{pm}$. oltuene standard colle-cted With a

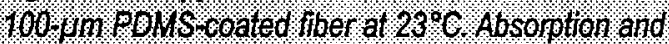
desorption were perfomed under dynamic conditions. For desomption the fiber was equifibrated at $10 \mathrm{~min}$.

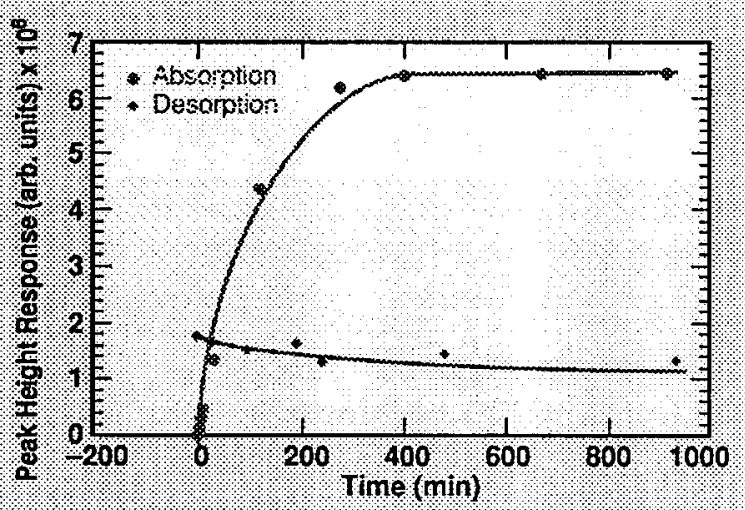

Figure 7. 19 .ppm toluene standard collected with a 75. in Carboxen-coated fiber al $23^{\circ} \mathrm{C}$. Absomption and desoption were perfomed under dymamic conditions. For desorption the fiber was first exposed to the toluene standard for $30 \mathrm{~min}$ and then left exposed for the specified time period: 
Although the advantage of the PDMS coating is its fast equilibration time during exposure, the same characteristic causes a problem in maintaining the sample intact until it is analyzed. Analyte losses can be minimized by capping the fiber syringe or putting it in cold storage, as discussed later in this report.

\section{B. "Polar fibers" (85- $\mu m$ Polyacrylate, 65- $\mu m$ Carbowax/Divinylbenzene)}

The PA coating is a cross-linked glass at room temperature and is deposited as a fully dense coating (as can be seen in the electron micrographs of surfaces and crosssections for the fiber coatings shown in Figs. $8 \mathrm{~b}$ and $9 \mathrm{~b}$, respectively). Although the identity of the PA used is unknown, the best-suited material would combine high thermal stability and a low $\mathrm{T}_{\mathrm{g}}$. One likely candidate would be polymethacrylate, which has a $\mathrm{T}_{\mathrm{g}}$ from 85 to $105^{\circ} \mathrm{C}$. At room temperature this material can be characterized as having low diffusion rates because of its high affinity for polar organics and relatively high $\mathrm{T}_{\mathrm{g}}$.

The carbowax/divinylbenzene coating is composed of a few percent CW adhesive that binds the DVB material,

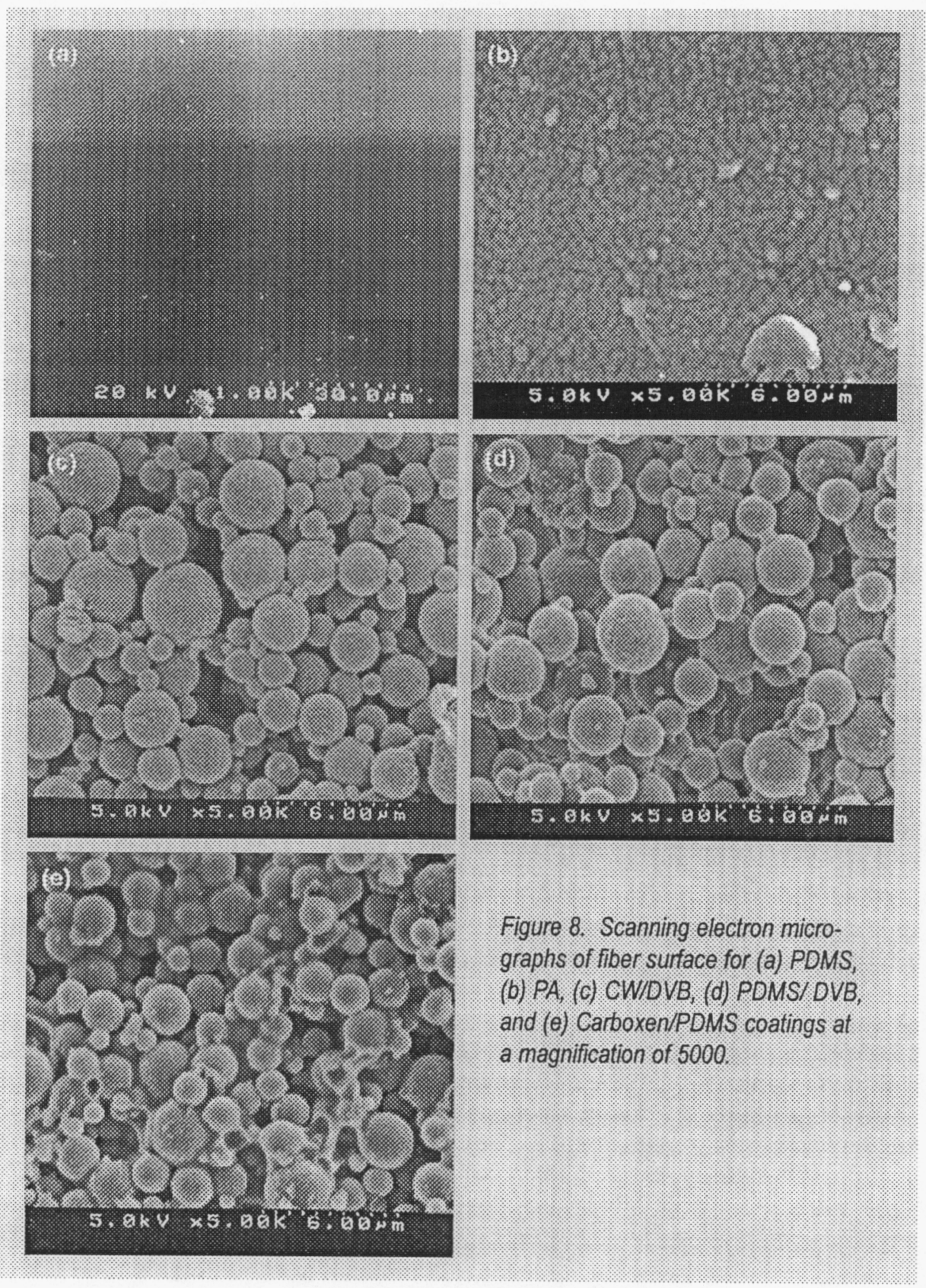



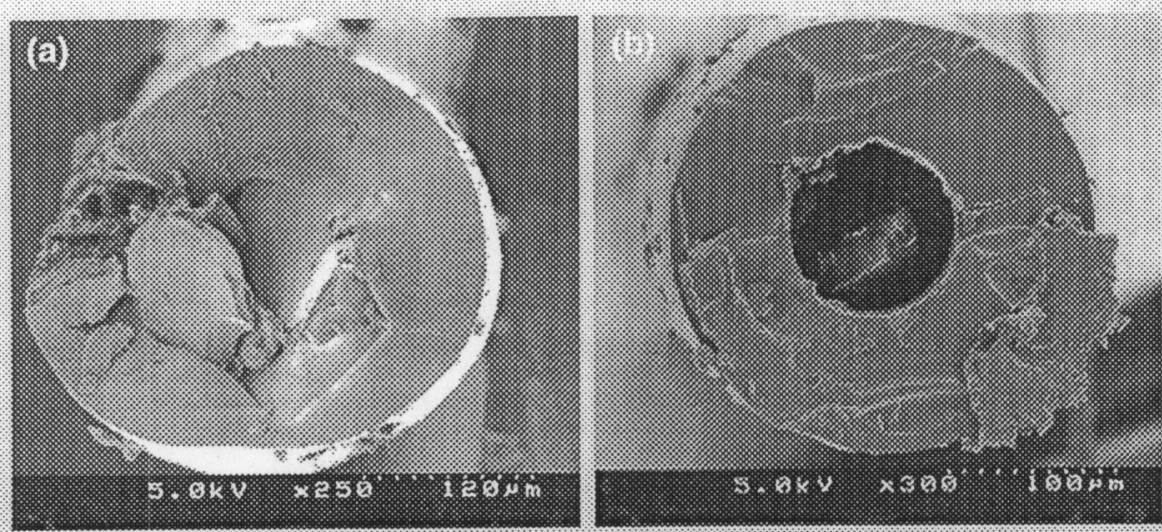

Figure 9 . Scanning elec. tron micrographs of fiber cross sections for

(a) POMS. (b) PA.

(c) CWIOVB.

(d) PEMS:OVB.

(e) Garboxen POMS, and

(1) $50130 \% \mathrm{~mm} 0 \mathrm{VB}$

Carboxen coatings at a magnification of 5000 .
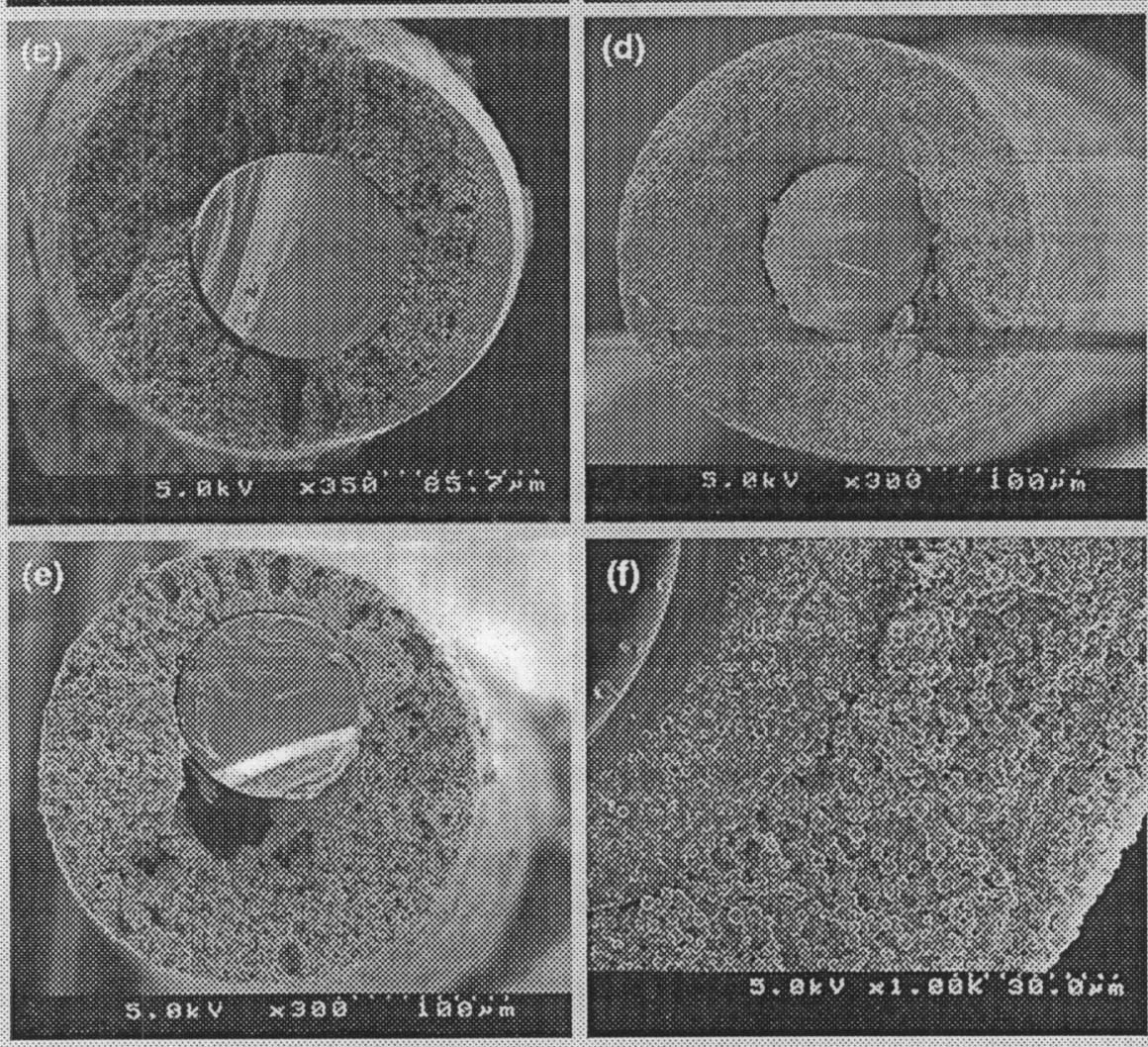

which exists as $1-$ to $5-\mu \mathrm{m}$ porous spheres. The DVB is a polystyrene cross-linked with divinylbenzene and has an estimated $\mathrm{T}_{\mathrm{g}}$ of 100 to $135^{\circ} \mathrm{C}$, giving this coating a characteristically low diffusion coefficient at room temperature. ${ }^{26}$ Although the $\mathrm{CW}$ binder, which is a polyethylene glycol (PEG), is considered to be an additional absorbent phase, its effects will be small compared to the styrene/DVB, especially at increased temperatures above the styrene/DVB $\mathrm{T}_{\mathrm{g}}$ and at long equilibration times.
C. "Bipolar fibers" (65- $4 \mathrm{~m}$ Polydimethylsiloxane/ Divinylbenzene, 75- $\mu \mathrm{m}$ Carboxen/Polydimethylsiloxane, and 50/30- $\mu \mathrm{m}$ DVB/Carboxen

The PDMS/DVB coating is similar to the CW/DVB coating described above except it uses a polysiloxane adhesive (e.g., PDMS) to bind the styrene/DVB spheres. The styrene/DVB is a glass at room temperature with a $\mathrm{T}_{\mathrm{g}}$ of 100 to $135^{\circ} \mathrm{C}$. As a result, its equilibration time for volatiles is much slower than the 100$\mu \mathrm{m}$ PDMS-coated fiber. For example, 1.9-ppm (v/v) toluene standard at $21^{\circ} \mathrm{C}$ equilibrates in approximately 
15 min as compared to 20 $s$ for the 100- $\mu \mathrm{m}$ PDMScoated fiber. In addition, we have found that the more polar coatings can lose some capacity when left under ambient conditions for extended periods of time. This decrease is shown in Fig. 10, where fibers were desorbed and then left unprotected under ambient conditions $\left(21^{\circ} \mathrm{C}\right.$, $35 \% \mathrm{RH}$ ) for approximately $18 \mathrm{hr}$ before being exposed for $15 \mathrm{~min}$ to a 1.9-ppm (v/v) toluene gas stream. The bipolar and polar coatings show small but significant drops in collection capacity when compared to direct collection after desorption. One explanation for this drop is that polar phases can accumulate moisture, which repels the less polar compounds.

The Carboxen coating consists of porous 1-to 5- $\mu \mathrm{m}$ carbon beads held together with a binder. The binder is a minor component at less than a few percent and is a polymer mixture that is a polysiloxane. The equilibration time for this coating with volatile non-polar compounds is extremely slow; however, the partition distribution is quite large. The exhibited absorption response is that of a diffusion-dominated process as seen in Fig. 7 , for the equilibration with a 1.9-ppm (v/v) toluene standard at $23^{\circ} \mathrm{C}$. However, the desorption is not the reverse of the absorption as found with the PDMS coating (see Fig. 6). Only 25\% desorption occurred after $15.5 \mathrm{hr}$ from a fiber loaded for $30 \mathrm{~min}$ with the 1.9-ppm (v/v) toluene standard. This would imply a surface adsorptiondominated process where the toluene binds to the Carboxen. With this particular coating, penetration occurs through the interstices and physisorption takes place at the carbon sites. The slow equilibration rate is indicative of a porous surface medium.

Carboxen exhibits the greatest affinity for highly volatile compounds. Detection in the low-ppt range can be achieved by GC/MS analysis. This high collection efficiency is attributed to strong hydrogen bonding interaction. However, the collection efficiency for more polar compounds is relatively low. This is seen in the comparison shown in Fig. 11 for a 20-min exposure of the 100- $\mu \mathrm{m}$ PDMS and 75- $\mu \mathrm{m}$ Carboxen fibers to an equilibrium headspace sample of polysulfide at $21^{\circ} \mathrm{C}$.

The 50/30- $\mu \mathrm{m}$ DVB/ Carboxen coating consists of a $30-\mu \mathrm{m}$-thick coating of the Carboxen formulation covered with a $50-\mu \mathrm{m}$ layer of the styrene/DVB phase. The binder is likely the same silicone PDMS adhesive used in the $65-\mu \mathrm{m}$ PDMS/DVB and 75- $\mu \mathrm{m}$ Carboxen/PDMS coatings. The two coating layers can be distinguished in the electron micrograph of the fiber cross-section as was shown in Fig. 9. The characteristics of this fiber are expected to be a combination of the Carboxen and PDMS/DVB coatings already described. This phase is an overall thicker phase, giving it a greater capacity and longer equilibration times than the thinner single-phase coatings.

\section{What factors affect sample-collection efficiency?}

The processes involved in microextraction headspace collection are the diffusion of analyte chemicals from the material to be sampled and absorption of them into the fiber coating. For headspace collection, temperature is the primary parameter that will affect collection efficiency for a given system. Higher temperatures will promote diffusion out of the sample material into the headspace; however, the partition coefficient between the headspace and coating will be lower. Other aspects of the fiber coating that affect collection efficiency are coating thickness, analyte affinity, matrix competition (if any), equilibration time, and headspace volume. Selection of the proper collection conditions will be determined by the instrument detection limit and sampling limitations. Headspace collection is normally performed on a weapon equilibrated at $23^{\circ} \mathrm{C}$ and collection time is limited to within 5 to $20 \mathrm{~min}$. The most difficult species to detect will be large polar compounds associated with polymer degradation products, because of their low volatility and the small diffusion coefficients of the fiber coating. Given the fact that equilibration is slow- 


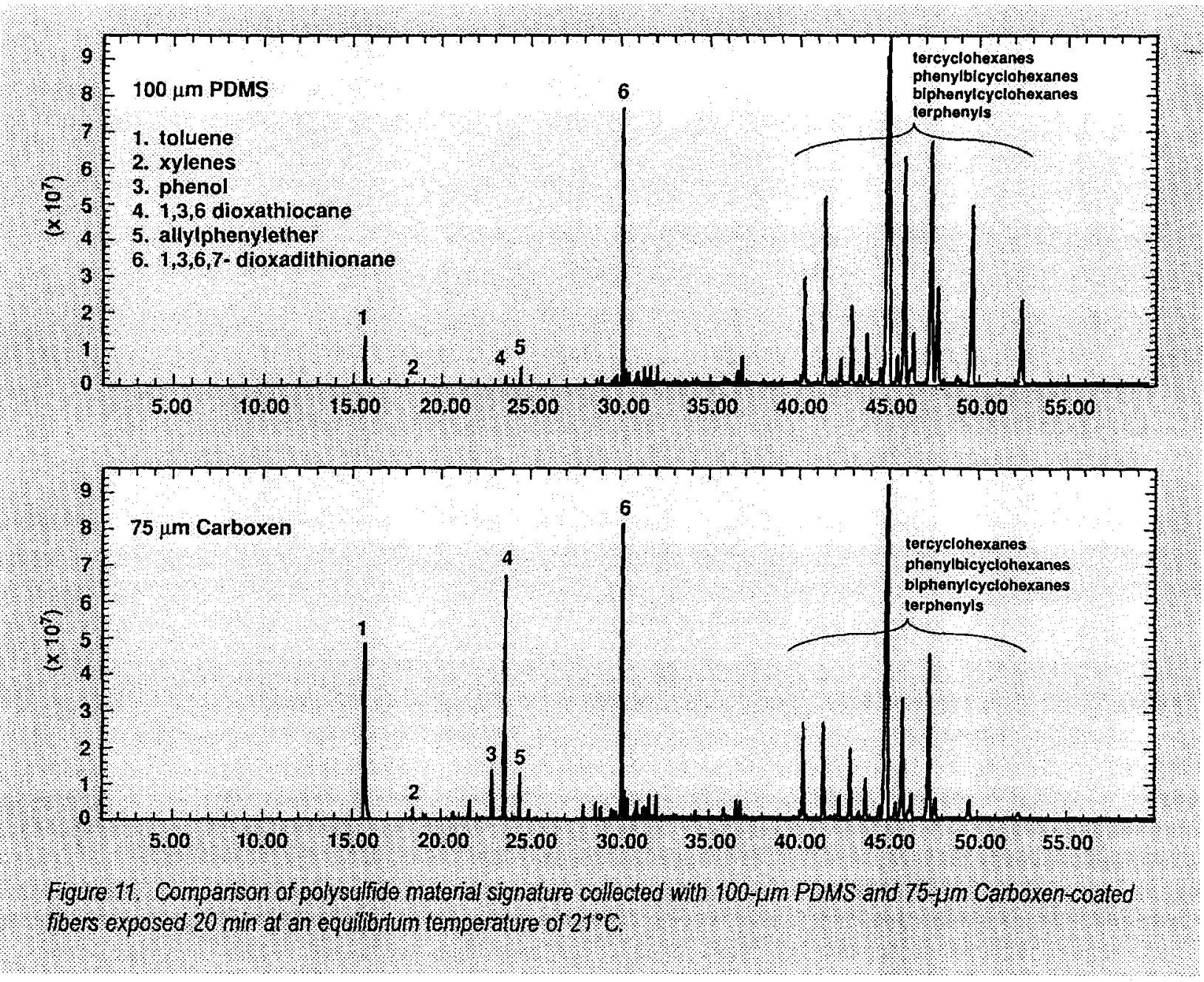

est for compounds that have the highest affinity for the fiber coating, a polymer with a fast diffusion rate might be the best for short collection times as was seen in Fig. 4 results.

\section{What properties affect accuracy and precision?}

The variables that need to be maintained for the most reproducible and accurate analysis in this application include thickness (i.e., volume) and integrity of the fiber coating, collection and storage temperature, sampling and storage time, matrix composition (e.g., humidity), contamination, stability of analysis equipment, and analysis technique. The control of these variables is discussed separately below.

\section{What is the most durable fiber?}

In this application, coating durability is measured by its stability during repeated desorption in the GC injection port, adhesion to the fused-silica shaft, cohesion of the coating, and compliance (i.e., flexibility, impact strength).

At this time the PDMS coating serves as the durability benchmark having the highest thermal stability, compliance (based on flexibility of the fiber), and adhesion to the fused-silica shaft. Thermal stability can be inferred in Table I by comparing procedural $T_{i}$ from thermogravimetic analysis of the fibers. In addition, the PDMS is a cross-linked polymer and is, therefore, a fully dense coating. It does not have a cohesion aspect like the CW, DVB and Carboxen coatings, which consist of $1-$ to $5-\mu \mathrm{m}$ spheres held together by an adhesive. Nevertheless, these latter coatings will likely improve in years to come with the development of new curing 


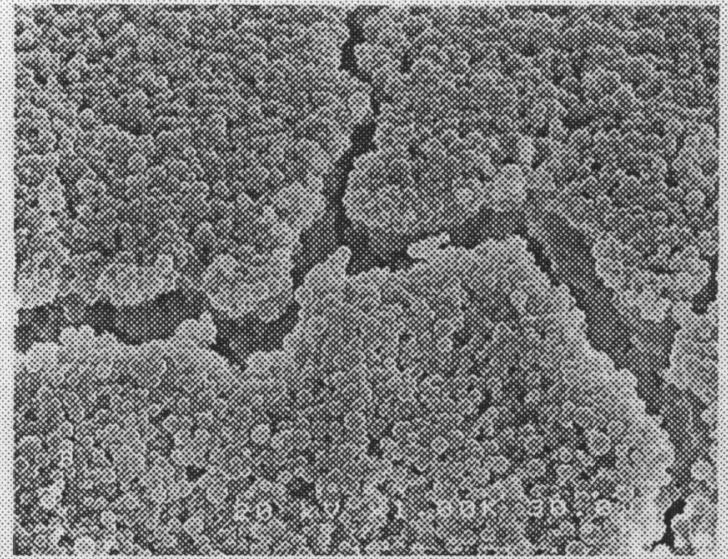

Figure 12. Scanning electron micrograph of PDMSIDVB surface showing fracturing of the coating. This type of fracturing is reduced in the newest lots, which appear to have greater amounts of PDMS adhesive.

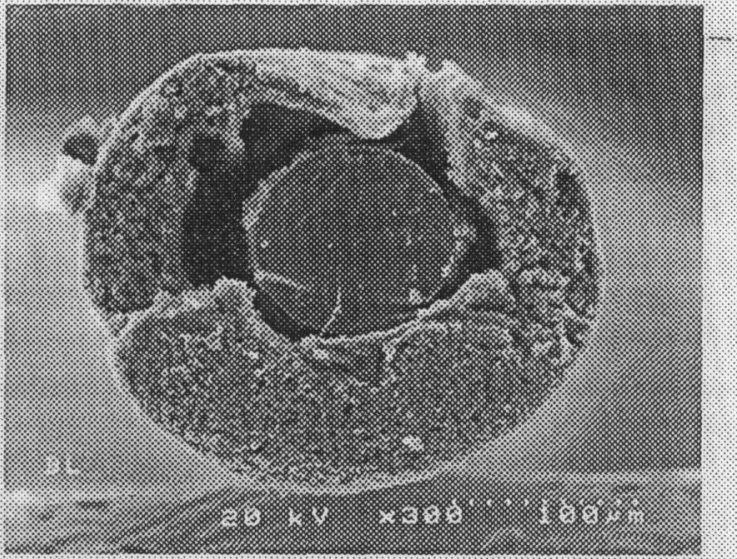

Figure 13. Scanning electron micrograph of Carboxen fiber cross section. Newest lots remained coupled bet: ter to the fised silica core after fracturing of the fiber: techniques, adhesion and cohesion coupling agents, and/or new coatings altogether.

The surface morphology of the PDMS/DVB coating has improved, as seen by comparing Figs. 8(d) and 12 From the scanning electron micrograph it appears that the amount of PDMS adhesive has been increased, thus reducing fracturing during manufacturing. However, it does appear to fracture when under stress, as can be seen in the cross-section photographs in Fig. 9.

Nevertheless, the coupling of the PDMS/DVB coating to the fused-silica shaft appears to have improved with respect to a previous lots of Carboxen/PDMS examined in June 1997 (compare Fig. 9(d) and Fig. 13). The PA and PDMS coatings appear to have the best coupling to the fused-silica shaft.

\section{How reproducible can collection and analysis be?}

The microextraction fibers are intended for repeated use. For an analysis, the fiber is sampled by thermal desorption in the GC injec-

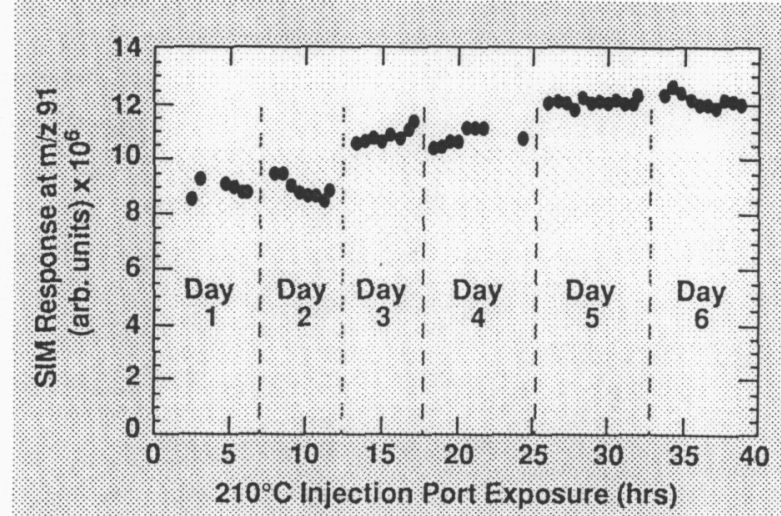

Figure 14 Equilibration collection of a 1-ppm toluene air standard using a 100 um POMS. Response is obtained by GCISIM at $\mathrm{m} / 2.91$. tion port, which typically is purged with a helium carrier gas and maintained from 200 to $250^{\circ} \mathrm{C}$. Under these conditions, repeated use of these fibers may result in degradation of the coating and flaking may result. However, the PDMS coating was found to be the most robust, showing no significant change in efficiency with prolonged use. In the study shown in Fig. 14, a 100- $\mu \mathrm{m}$ PDMS-coated fiber was used repeatedly to sample a 1$\mathrm{ppm}(\mathrm{v} / \mathrm{v})$ toluene doped air standard. The study lasted six days over which 52 analyses were performed. Each data point represents an analysis whereby the fiber is exposed to the toluene standard for $5 \mathrm{~min}$ and then injected into a GC injection port maintained at $210^{\circ} \mathrm{C}$. The toluene response versus accumulated exposure time in the injection port is plotted for each analysis. Response was measured by single ion monitoring MS at ion mass-to-charge ratio $(\mathrm{m} / \mathrm{z})$ of 91 . The variation within a particular day is likely the result of experimental error with a relative standard deviation (RSD) of 1 to $3 \%$. The day-to-day drift of approximately $20 \%$ is attributed to instrument drift. 


\section{What is the long-term reproducibility and lifetime benchmark for the fibers?}

In the reproducibility study described above, the fiber was left in the injection port during each $45-\mathrm{min}$ GC run to prolong its exposure. For the duration of this study, we did not see any degradation in the fiber collection efficiency over a total of approximately $40 \mathrm{hr}$ at an injection port temperature of $210^{\circ} \mathrm{C}$. Given a typical desorption of $3 \mathrm{~min}$, this would equate to at least 800 injections.

\section{What kind of lot-to-lot reproducibility can be achieved?}

We compared four different lots of 100- $\mu \mathrm{m}$ PDMScoated fibers that were manufactured over a period of one year. For the volatile non-reactive compounds (i.e., benzene and toluene), we achieved 3.5 and $2.9 \%$ RSDs, respectively, as shown in Fig. 15. This is not significantly greater than the precision obtained from repeated analysis using the same fiber, as shown in Fig. 14. Compound selection for this assessment is important. A reactive compound such as butanoic acid yielded an RSD of $22 \%$. Trimethylamine, a compound with a high surface affinity (i.e., a sticky compound), yielded a $5.7 \%$ RSD.

\section{Is there any competition between species that will interfere with quantification?}

Most of the data available comparing coating efficien-

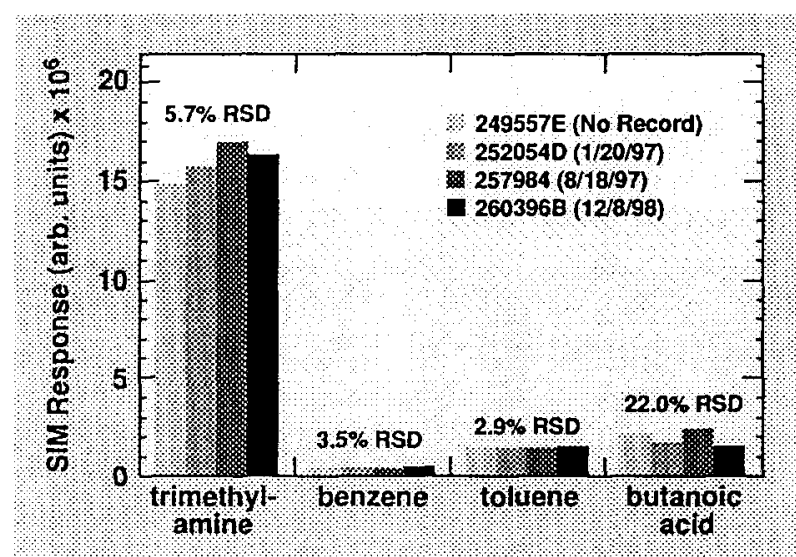

Figure 15. Companison of response representing (1) reactive, (2) and (3) volatile tow surace activity, and (4) semivolatile high surface activity compounds tor dif. ferent lots of 100. $\mu \mathrm{m}$ PDMS coated fibers: cy is performed in or over a liquid phase. Under these conditions, the sample matrix can drastically change the distribution constant as well as equilibration time by altering the characteristics of the coating or displacing other lower affinity analytes at the absorbent surface. This is not the case for gas phase collection involving an inert gas matrix such as $\mathrm{Ar}, \mathrm{N}_{2}$, and zero grade air (i.e., common weapon-purge gases). The permanent gas matrix of the weapon has a low affinity for the coating materials and does not influence collection efficiency.

Absorption competition was evaluated for different species at concentrations within the range of those found in the weapons and aging/compatibility test units. For this evaluation, response curves for different compounds were produced by collection and analysis of a gas mixture. The different concentrations were produced using a gas standards generator and combining permeation tubes of the different compounds. Gas permeation tubes consist of slightly permeable polymer membranes that outgas an encapsulated compound. They are calibrated gravimetrically by measuring weight loss over time as the compound diffuses out of the tube. The concentration of this mixture is changed by adding a diluent gas flow.

As shown in Fig. 16, the response curves for all the compounds remained linear with increasing concentration. The gas permeation tube for perfluoromethylcyclohexane was the lowest emitting tube yielding 0.8 to $46.9 \mathrm{ppb}(\mathrm{v} / \mathrm{v})$, whereas the highest emitting tube was for toluene yielding 26.5 to $1560 \mathrm{ppb}(\mathrm{v} / \mathrm{v})$. These results show that under suitable conditions collection competition effects can be avoided.

Although linear response is ideal for obtaining quantitative results, relative response is still dependent on the absorption efficiency of the fiber coating, thermal stability during separation, and ionization efficiency of the MS source. As a result, working curves for each compound needs to be produced to achieve accurate quantification. 


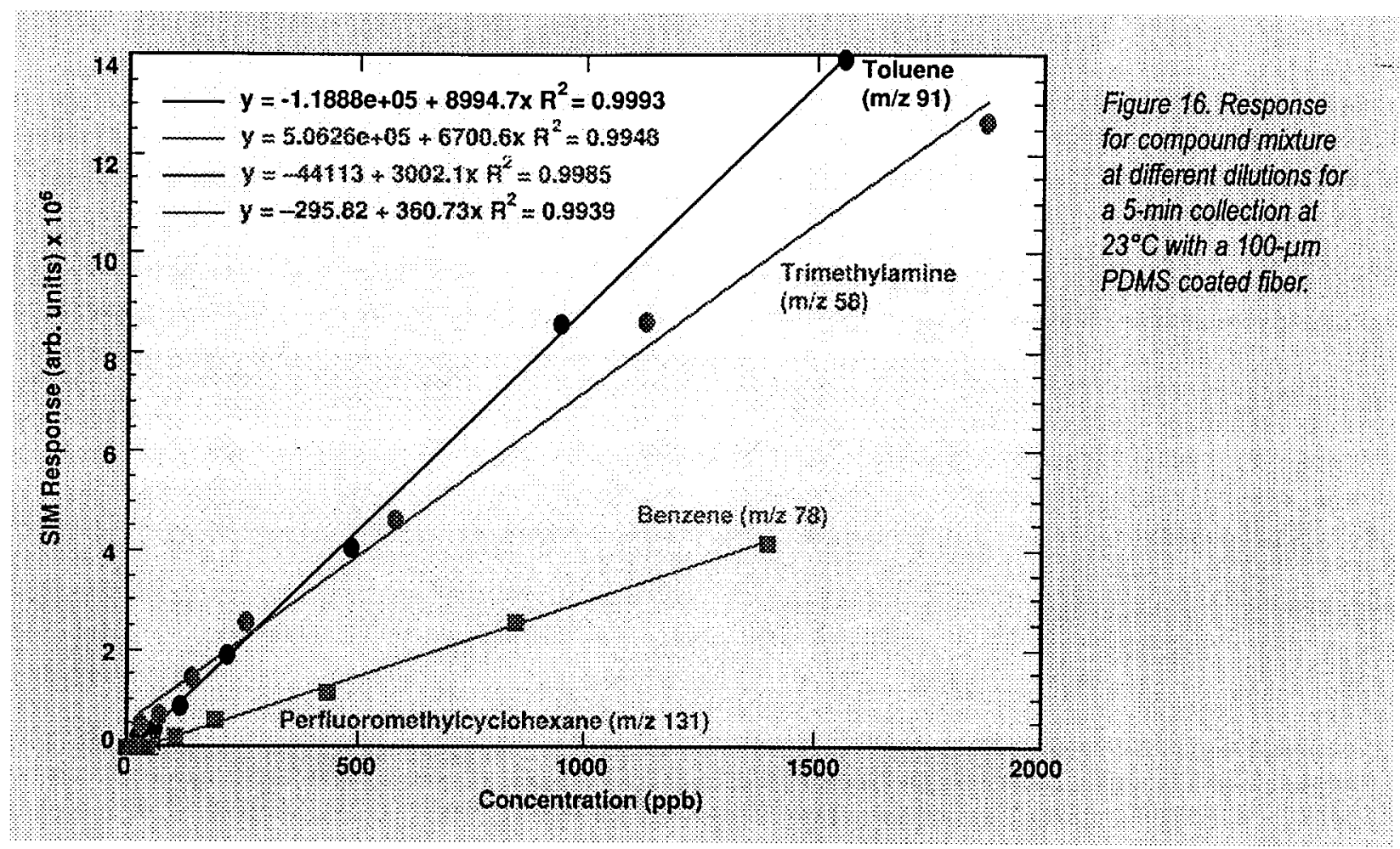


Solid Phase Microextracrion for the Analysis of Nuclear Weapons 


\section{What is the most practical approach to quantify a sample or weapon headspace?}

Apart from fiber selection, quantification is perceived to be one of the biggest issues associated with application development. We approach quantification by either of two methods-direct comparison with a known standard or discontinuous extraction-depending on whether the collection alters the headspace concentration.

\section{A. Direct comparison}

If sequential sampling does effect the sample headspace concentration, we are able to deduce concentration directly by comparing sample response with a known standard produced under similar collection conditions (e.g., fiber coating, collection time, temperature). For this work, where the concentrations typically fall in the low ppm to ppb range, we used a gas standards generator (GSG) (Kin-Tek, Model 585) to produce accurate standards. The GSG is a gas dilution system used to produce a broad range of concentrations from a diffusion source. Here we use a gas permeation tube as the diffusion source, which consists of a compound sealed in a Teflon tube. The permeation rate of the chemical through the Teflon wall is determined by a separate gravimetric measurement. The concentration is changed by varying the dilution gas flow rate. More than one permeation tube can be placed in the GSG outgas oven to create a calibration signature, thus, producing results like those shown in Fig. 16.

\section{B. Discontinuous extraction}

For analyses of small samples or where the collection depletes the headspace concentration, we used a discontinuous gas extraction approach to estimate total headspace concentration. Headspace concentration can be calculated using the decreasing response such as that seen in Fig. 17 by the following:

$$
A_{\text {Total }}=\sum_{i=1}^{i=\infty} A_{i}=\frac{\left[\left(A_{1} A_{2}\right)^{7}\right]^{1 / 8}}{\left[\left(A_{1} A_{2}\right)^{1 / 4}-\left(A_{3} A_{4}\right)^{1 / 4}\right]\left(A_{3} A_{4}\right)^{1 / 8}}
$$

where ATotal is the analysis response and the subscripts indicate the sampling sequence number. This analysis assumes that when each sample is collected the system has achieved equilibrium. Following this sequential analysis we can limit the number of samples to one if we assume that the headspace response for each subsequent extraction follows the exponential law:

$$
A_{i}=A_{1} e^{-(i-1) k}
$$

where $\mathrm{k}$ is a system specific decay constant that can be deduced from the equation (1) experiment using the following form of equation (2):

$$
A_{\text {Total }}=\frac{A_{1}}{1-e^{-k}}
$$

The results shown in Fig. 17 compare toluene response following subsequent headspace analysis from two different LX-17-1 samples. For these analyses, we sonicated $10 \mathrm{mg}$ of LX-17-1 with 1-ml water in a sealed 2$\mathrm{ml}$ glass ampule for approximately $6 \mathrm{hrs}$. Following the sonication, the vial was sealed in a standard $20-\mathrm{ml}$ headspace vial and then broken open by shaking. This transfer to the larger headspace vial, which uses a septum crimp cap, permits sampling with the microextraction syringe. With each consecutive sampling of the headspace vial, the concentration drops. Using the approach described above, the value of $k$ for sample analyses 1 and 2 were similar, equaling 0.797 and 0.800 , respectively.

To evaluate whether the system maintains equilibrium throughout the analysis, we collected an additional sample at least three hours after the fifth sampling. As shown in Fig. 3 there is only a slight increase in response over that for the previous sampling, which is an insignificant change compared to the initial sample response. 


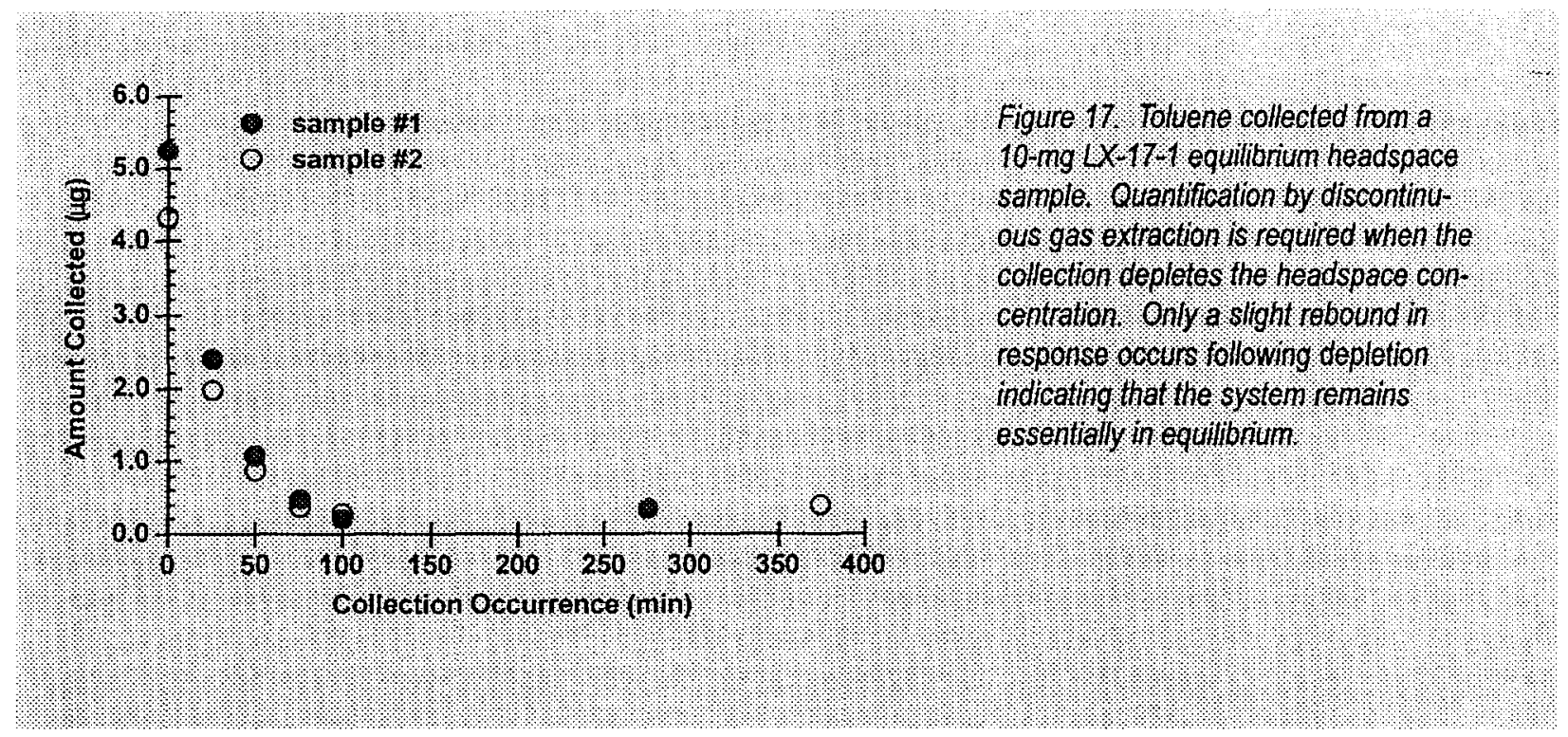

\section{How do we know we are using the right fiber?}

Coating selection in this application is determined by the collection time and temperature, target species, and headspace concentration. For analysis of weapon or aging/compatibility test units, the main issue is one of sensitivity, which is limited by short exposure times and low concentrations.

Practical exposure times during weapon disassembly are limited to less than $20 \mathrm{~min}$. This permits completion of the full gas-sampling procedure between technician work breaks. As a result, reaching equilibrium between the headspace and fiber coating is not possible. Because most of the targets fall within the mid- to low-volatility range and are at low concentrations at room temperature, the best coating is one with the highest free-volume mobility at room temperature (e.g., the PDMS coating). The thickest coating of $100-\mu \mathrm{m}$ drives the fastest uptake as shown in Fig. 4. Although DVB and PA coatings might have a higher affinity for the targets, they have much lower diffusion rates because they are polymer glasses at room temperature.

In theory, sensitivity for a target compound can be related directly to the instrument response using the distribution constant, $\mathrm{K}_{\mathrm{fh}}$, between the fiber coating and weapon headspace. This approach can be used to predict the minimum concentration detectable in the weapon headspace or to identify the best coating for a particular compound. Assuming that the analyte vapor in the headspace behaves as an ideal gas (i.e., $\mathrm{pV}=\mathrm{nRT}$ ), the $\mathrm{K}_{\mathrm{fh}}$ will equal the ratio of the concentration in the fiber coating, $\mathrm{C}_{\mathrm{f}}$, to the headspace concentration, $\mathrm{C}_{\mathrm{h}}$. The fiber/headspace distribution constants can be extrapolated from isothermal GC retention times if fiber and column use a similar coating material. ${ }^{27}$ This can be performed readily with the PDMS-coated fiber because PDMS is also a common column stationary phase material. The $\mathrm{K}_{\mathrm{fh}}$ estimation formula using this approach is as follows

$$
\begin{aligned}
& K_{f h}=\left(t_{R}-\frac{t_{A}}{T_{m}}\right) \frac{F T_{c}}{T_{m}} \times \frac{P_{m}-P_{w}}{P_{m}} \times \\
& \frac{3}{2} \times \frac{\left(P_{i} / P_{o}\right)^{2}-1}{\left(P_{i} / P_{o}\right)^{3}-1} \times \frac{1}{V_{L}}
\end{aligned}
$$

where $t_{R}$ is the compound retention time, $t_{A}$ is the retention time of an unretained specie, $F$ is the column flow measured with a flow meter, $\mathrm{T}_{\mathrm{c}}$ is the temperature of the column, $T_{m}$ is the temperature of the flow meter, $p_{m}$ is the flow meter pressure, $p_{w}$ is the pressure of saturated water vapor, $p_{i}$ is the GC inlet pressure, and $p_{0}$ is the column outlet pressure. 


\section{What is the right coating thickness?}

Coating thickness directly impacts quantification and detection limits. The best route for quantification is to achieve equilibrium with the headspace gas. Once equilibration is achieved, exposure time is no longer a variable. Although the thinnest and most permeable coatings provide fast equilibration, they have a smaller capacity, resulting in lower efficiency. For the sampling of nuclear weapons, where we want to collect less volatile species, such as polymer degradation products, it is best to use a thick coating. This approach is demonstrated in Fig. 18, in which we evaluated collection efficiency of the PDMS coating using a 200-mg equilibrium headspace sample maintained under ambient conditions (i.e., $23^{\circ} \mathrm{C}, 35 \% \mathrm{RH}$ ). Coating thicknesses of 7 , 30 , and $100 \mu \mathrm{m}$ were compared. Each fiber was exposed to an equilibrium headspace standard of TNT for different times from $1 \mathrm{~min}$ to $16 \mathrm{hr}$. Equilibration occurred the fastest for the thinnest coating, that is, within $2.5 \mathrm{hr}$, while the $100-\mu \mathrm{m}$ coating had not yet equilibrated within $17 \mathrm{hr}$. Nevertheless, the $100-\mu \mathrm{m}$ coating is able to absorb a greater amount at a given time than the thinner coatings, which is attributed to its larger surface area. This trend can be deduced by comparing relative response for the 7-, 30-, and 100- $\mu \mathrm{m}$ PDMS-coated fibers for a 20-min exposure.

\section{What is the recommended collection time?}

Ideally, the collection time should accommodate the compound with the longest equilibration time. The advantage of taking this approach is that once equilibration has been achieved, exposure time is no longer critical for quantification; however, there can be exceptions (e.g., compound reactivity, displacement by a slowly diffusing compound). If it is not possible to wait for equilibration, then the longest possible time-controlled exposure time should be used. Temperature should be carefully regulated for the DVB and PA coatings as the $T_{g}$ is approached.

Equilibration time can be estimated using the following expression:

$$
t_{e}=t_{95 \%}=\frac{x_{o}{ }^{2}}{2 D_{f}}
$$

where $x_{o}$ is the thickness of the polymer coating and $D_{f}$ is the diffusion coefficient of the fiber coating. This expression assumes that equilibrium has been essentially achieved when $95 \%$ of the equilibration concentra- tion exists in the fiber coating. ${ }^{28}$ This value can be determined experimentally by varying the exposure time of the fiber to a calibrated gas standard stream.

In the example shown in Fig. 6, the 1.9-ppm (v/v) toluene standard generated with a gas standards generator was collected with a $100-\mu \mathrm{m}$ PDMS-coated fiber. Equilibration was achieved within 32.6 seconds at $23^{\circ} \mathrm{C}$, which corresponds to a diffusion coefficient of $1.5 \mathrm{x}$ $10^{-6} \mathrm{~cm}^{2} / \mathrm{s}$. The literature value at standard temperature and pressure is $2.5 \times 10^{-6} \mathrm{~cm}^{2} / \mathrm{s}$. The smaller experimentally determined value might be the result of a lower effective temperature condition of the fiber compared with the literature conditions, or a thinner than expected fiber coating.

\section{What are the collection constraints for performing microextraction analysis on weapons?}

To remain transparent to other core surveillance activities and fall within the nuclear safety guidelines, headspace analysis of the weapons requires a procedure that (1) can be performed under ambient temperature; (2) has practical collection times of less than $20 \mathrm{~min}$; (3) maintains the integrity of the weapon gas volume; (4) provides reproducible and quantitative results; and (5) can identify all possible targets. For microextraction, the most challenging objective is one of achieving sufficient sensitivity. If the different headspace chemicals are in high concentration, then collection can be done with gas bottles, as is the case for the permanent gases. As it turns out, many polymer degradation products are high molecular-weight polar compounds. These species

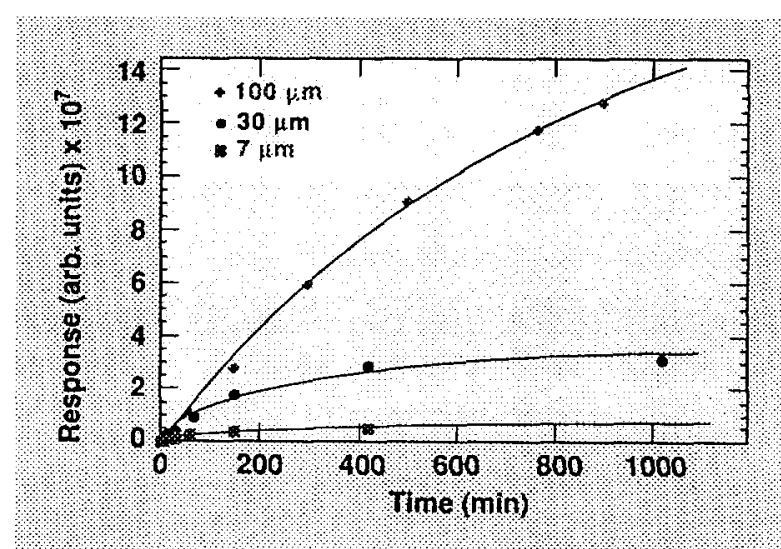

Figure 18. Comparison of $200 \mathrm{mg}$ equilibium head: space samples of TNT under ambient conditions (I.e. $23^{\circ} \mathrm{C}, 35 \% \mathrm{RH}$ ) as a function of time for different thick- 
are in the weapon headspace at low- and sub-ppb concentrations and are difficult to collect given their high surface activity.

In addition, we have found that significant losses of even volatile compounds occur when trying to sample downstream through the gas-manifold vacuum lines. Although losses can be minimized by heating the transfer lines, this solution is impractical from a safety standpoint. The best alternative is to move the fiber as close as possible to the source. Shown in Fig. 19 is a comparison of chromatograms of B83 weapon signatures taken at three different sampling locations-at the Blue Goose gas bottle port, at a tee $50-\mathrm{cm}$ downstream, and at the weapon purge valve. At the two downstream locations (i.e., at the Blue Goose and 50-cm tee) the less volatile compounds are not detected starting at an elution time of approximately $20 \mathrm{~min}$. (Note: The signature seen at the $50-\mathrm{cm}$ tee starting at $30 \mathrm{~min}$ is background mainly from carry-over that remains in the gas manifold transfer lines and is subtracted from the chromatogram before interpretation.) At the purge valve, the microextraction sampler remained in contact with the weapon headspace for approximately $20 \mathrm{~min}$. We are able to collect and identify for the first time polymer degradation products from silicone and polysulfide materials.

Given the short collection times and ambient collection conditions, a fiber coating with either a high diffusion coefficient is needed. The $100-\mu \mathrm{m}$ PDMS is a good compromise for collecting a broad range of compounds. The thickest of the PDMS coatings can collect and equilibrate highly volatile compounds within minutes and has sufficient capacity and affinity to achieve low ppb detection. The high diffusion coefficient afforded by its rapid free-volume mobility at room temperature makes it well suited for collection of compounds with low volatility given short collection times. In addition, the high-mechanical and thermal stability of the PDMS coating yields a relatively high level of durability and reproducibility. Nevertheless, we have used the Carboxen fiber for the detection of highly volatile compounds at low ppt levels. The difficulty in using a high-affinity fiber such as the Carboxen is that trace analysis is susceptible to contamination. Because it is not always possible to run controls on the gasmanifold system, we can only confirm the detection of volatiles collected with the Carboxen-coated fiber with analyses using other coatings and gas bottle results.

\section{How long can the samples be stored after collection?}

Sample storage is not required when collection and analysis can be performed in the laboratory, as with material standards and parts. However, for monitoring nuclear weapons, it is more practical to sample in the surveillance bay and transport the collector back the laboratory for analysis. This may result in a delay on the order of hours, which might require temporary sam-

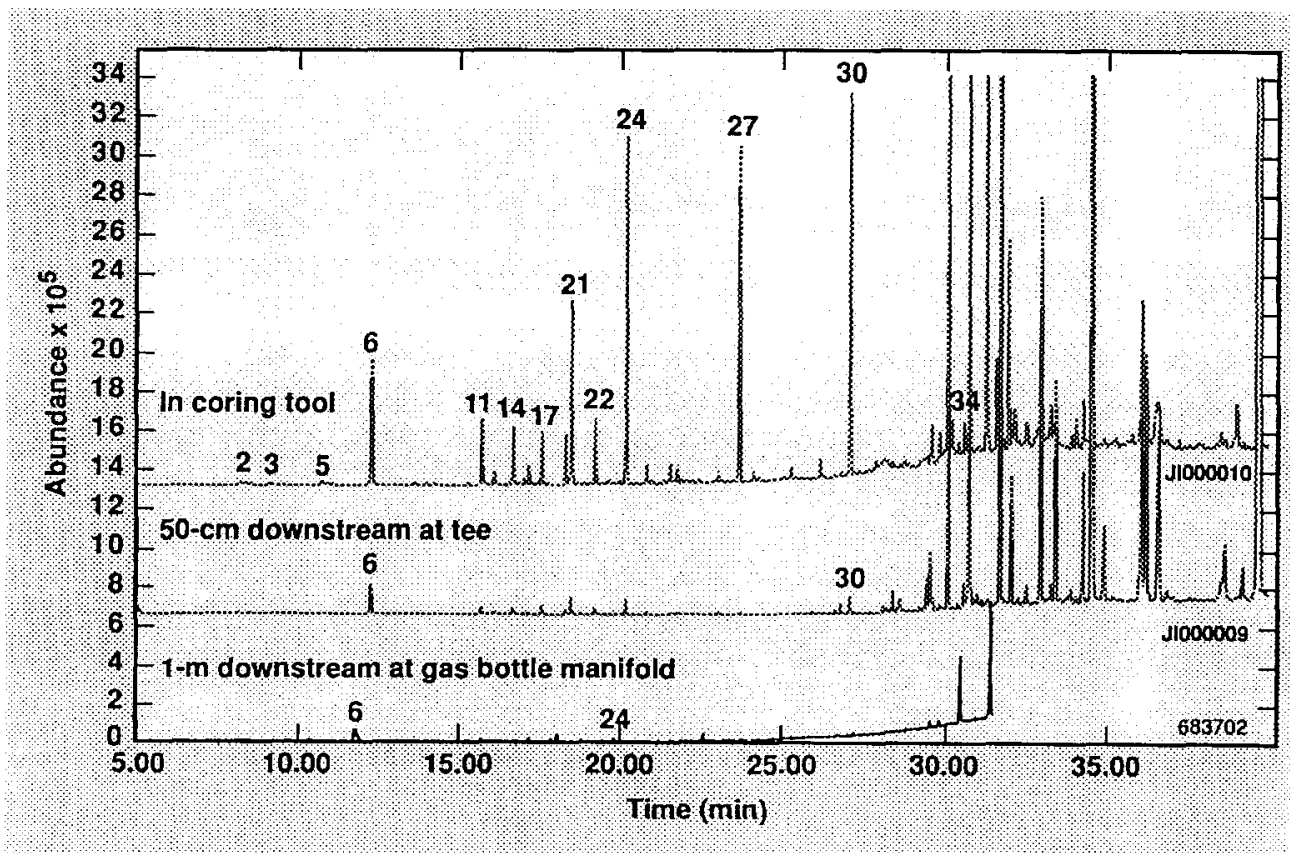

figure 19 Companson of $B 83$ primany head: space signatures collected at difterent loca. tions downstream from the weapon purge. valve. Losses from surface adsoiption within the gas-sampling vaceum manifold (10.) Blue Goosel make direct exposure of the fiber necessany for oblaining a representative profile of the weapon headspace. Peak numbers correspond to compound list shown in Fig. 2 . 
ple storage. If a fiber is left unprotected, the sample loss will be determined by the type of analyte and coating. For example, complete desorption of toluene from an exposed 100- $\mu \mathrm{m}$ PDMS coated fiber left free-standing will occur within 20 seconds, whereas the Carboxen coated fiber retains $80 \%$ of the toluene over a $15.55 \mathrm{hr}$ period (see Fig. 7). Desorption losses can be reduced significantly by retracting the fiber within the protective delivery syringe. In the example shown in Fig. 20, a $100-\mu \mathrm{m}$ PDMS coated fiber is loaded with a 100-ppb $(v / v)$ toluene gas standard and then retracted into the syringe sheath. After the fiber has been allowed to stand for approximately 2 hours, the loss is limited to approximately $50 \%$.

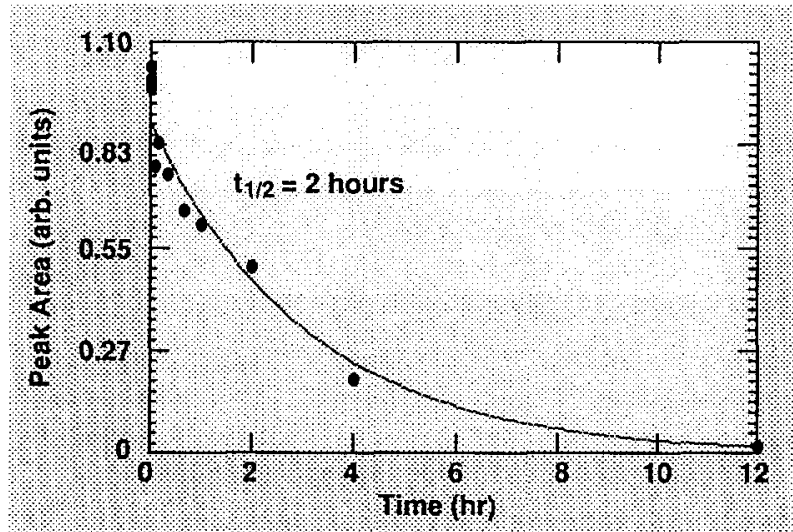

Figur 20 Loss of toluene trom a 100 Hm POMS-coat ed fiber that was left retracted inte its protective syinge.
Although fiber selection in this case would be in favor of the coating with the slowest desorption rate, we have found that loss can be minimized by keeping the fiber enclosed within the microextraction sampler and capping the syringe with a low permeable polymer such as Teflon. This approach is shown in Fig. 21, where we compare polysulfide headspace analyses of the 20 most intense compounds after being stored for $3 \mathrm{~min}$ and for $28.5 \mathrm{hr}$. In this experiment, approximately $1 \mathrm{~g}$ of polysulfide material was equilibrated in a headspace vial at $21^{\circ} \mathrm{C}$ overnight. After exposing a $100-\mu \mathrm{m}$ PDMS fiber to the headspace for $20 \mathrm{~min}$, the fiber was stored in the protective syringe with a Teflon cap. The average loss was approximately $12 \%$. Most of the loss likely occurred from absorption by the fiber-assembly sealing septum (see Fig. 3). This is evident by the presence of compounds that are known to outgas from this septum. It has been suggested that storage efficiency can be improved by cold storage of the collector, although we have not yet studied this approach.

The sealing septum is a more problematic source of contamination for the Carboxen fiber. This is because the fiber coating has a high affinity for non-polar volatile compounds (see Fig. 7) while the sealing septum, which is a silicone material, does not. Chemicals that persist in the sealing septum from the time of manufacturing outgas and can be accumulated by the Carboxen coating if capped for long periods of time. In addition, when the Carboxen fiber assembly is degassed in high vacuum, the coating accumulates out-

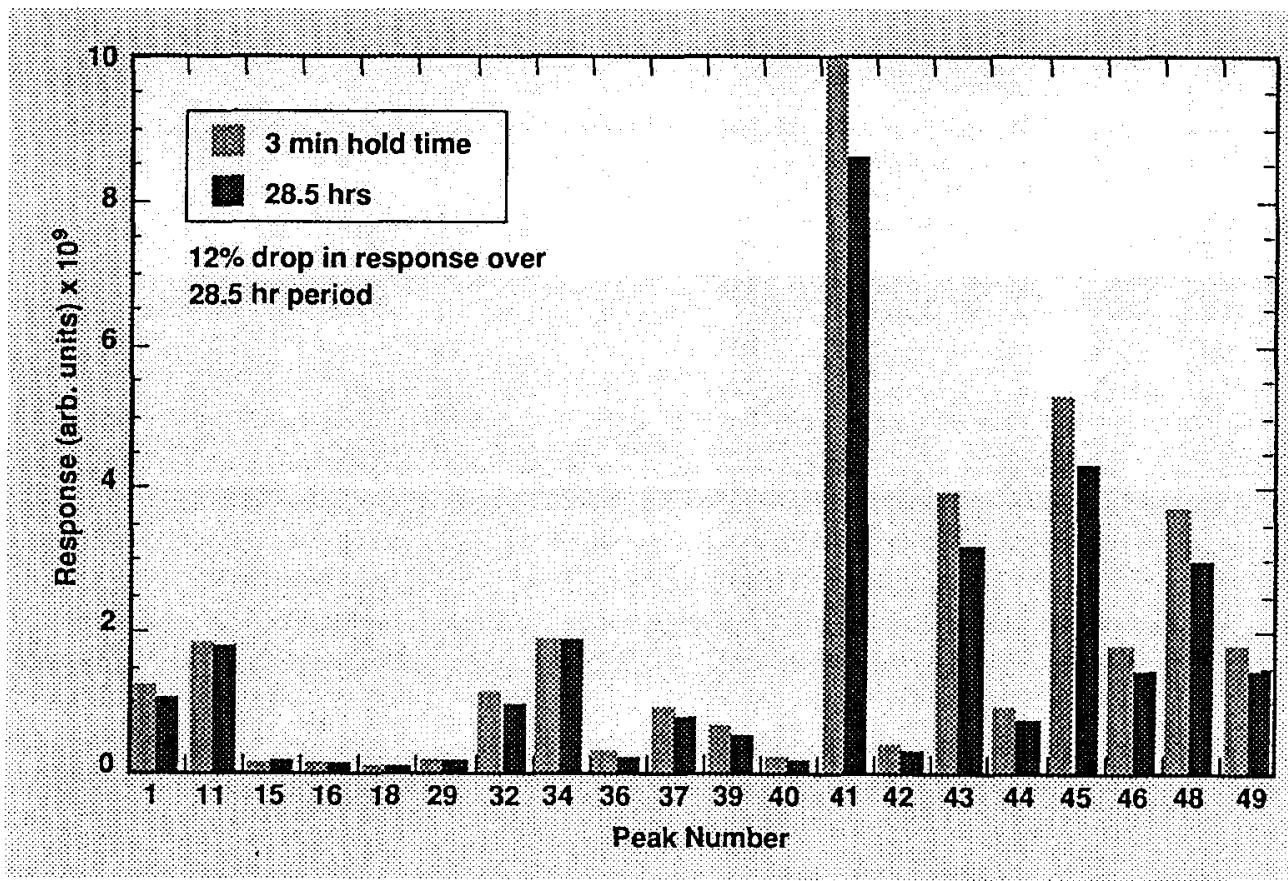

Figure 21 Effect of: long term storage on response tor 100.um POMS. coated fiber sealed in the syinge with a Teflon cap. Losses. are believed to occur through absomption by the fiber assembly seal. ing septum. 
gassed species from the sealing septum, whereas the PDMS coating does not. This can be seen by comparing the fiber blanks for the different coatings after evacuation on a gas manifold as shown in Fig. 22.

\section{What are currently the major application limitations?}

Contamination interference is the primary limitation currently facing weapon headspace and material analysis. In weapon analysis we are detecting significant levels of residue remaining in the gas sampling manifold system from previous samplings. This is demonstrated in Fig. 23, where we compare a fiber blank and a gas manifold system control sample with a weapon sample, all collected with a 100-mm PDMS coated fiber. The fiber blank will reveal any contamination that might be left on the fiber and fiber assembly and in the GC/MS system. As shown in Fig. 23a, the procedures have evolved to the point where the instrument and fiber blanks are essentially free from contamination interferences. The system control blank shown in
Fig. $23 \mathrm{~b}$ was taken with the weapon purge valve closed, but with the Blue Goose manifold attached and evacuated. In the system control blank, the semivolatile response is near the same as that seen for the weapon sample. Even volatile compounds with relatively high vapor pressure of over 1000 Torr at room temperature are seen in the process control sample.

Although carryover or memory effects such as that shown in Fig. 23 may not be a problem for permanent gas and highly volatile compound analyses, it does complicate signature interpretation and lower quantification accuracy. We believe that future success in weapon material and atmosphere analysis will require new procedures that eliminate or at least reduce such carryover. Furthermore, it may be necessary to remove these volatile and semivolatile compounds for the benefit of other measurement devices such as chemical sensors (e.g., moisture). In fact, poor long-term accuracy and stability of moisture analysis data recently identified in weapon surveillance at Pantex may be attributed in part to the build up of semivolatile residue on the moisture probes.

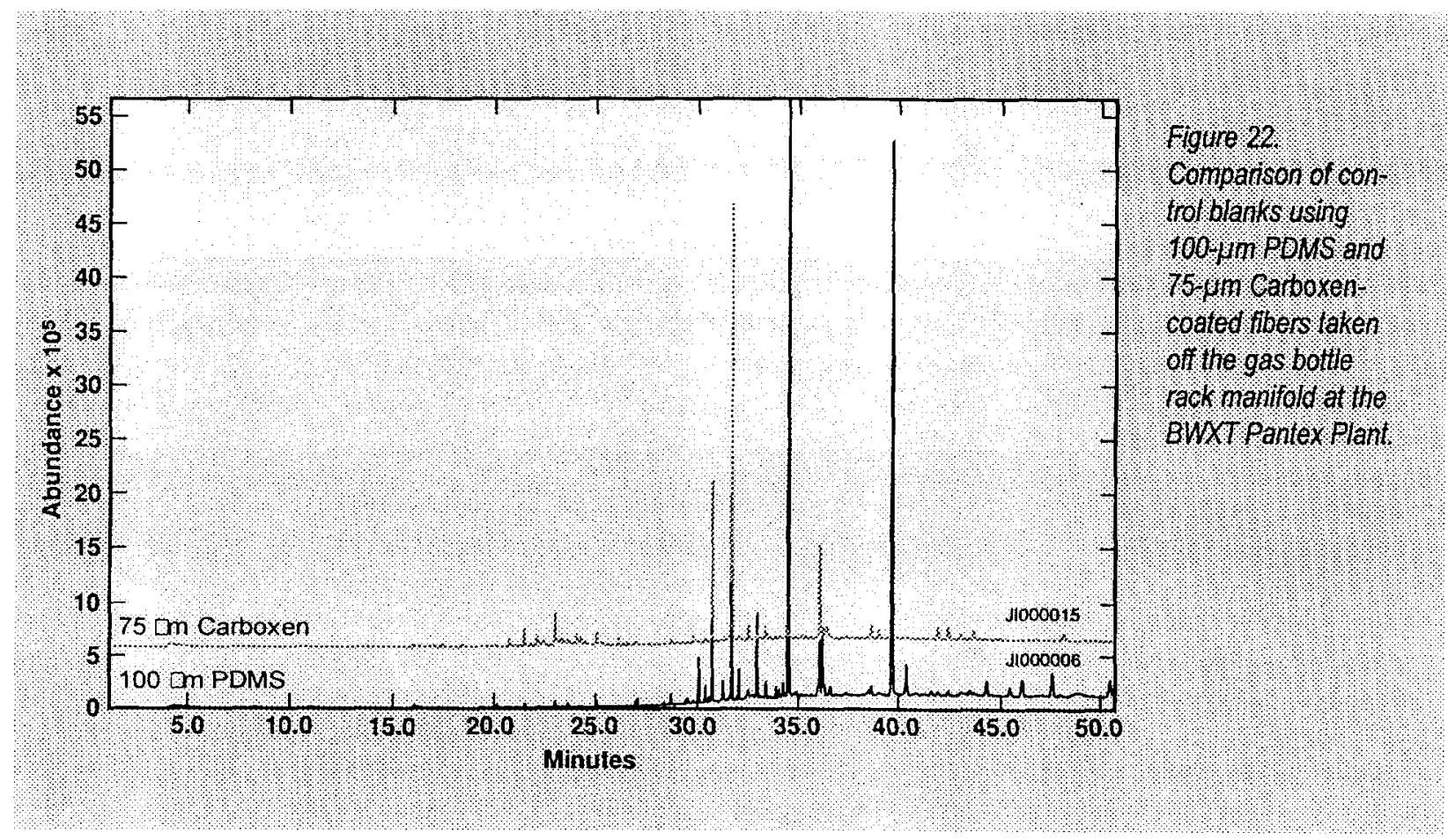




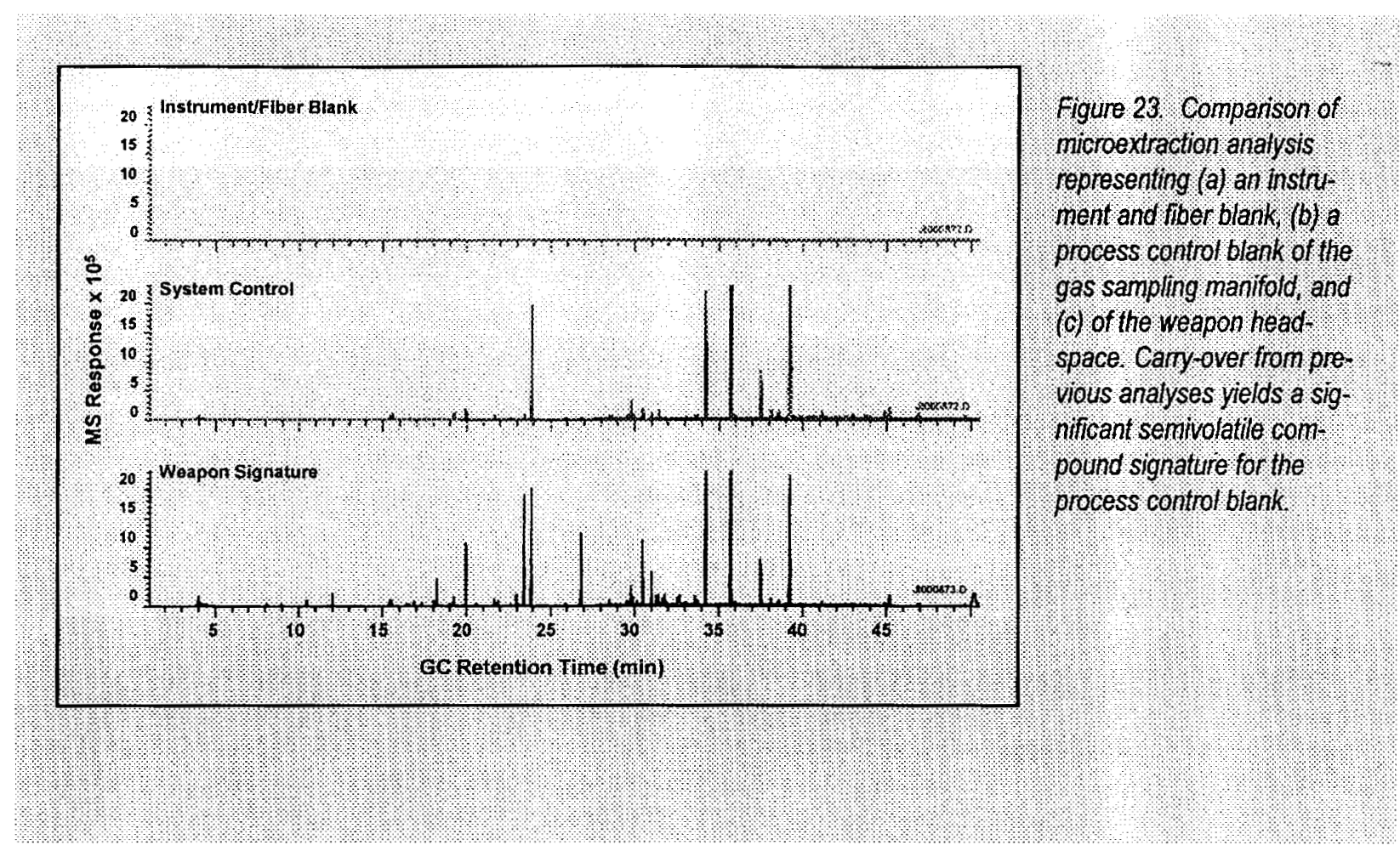


activated charcoal - an amorphous form of carbon characterized by high adsorptivity for many gases and vapors. The carbon is made by destructive distillation of carbonaceous materials (e.g., wood, nut shells, animal bones). Activation is achieved by heating the carbon to 800 to $900^{\circ} \mathrm{C}$ with steam or carbon dioxide. The average internal surface area is on the order of $1000 \mathrm{~m}^{2} / \mathrm{g}$.

aldehyde - a compound with a functional group consisting of a hydrogen bonded to a carbonyl carbon (i.e., $\mathrm{C}=\mathrm{O}$ ) The generic aldehyde structure is:<smiles>CC=O</smiles>

alkane - an organic compound containing carbon that is only singly bound to other carbon atoms or hydrogen. Some typical alkanes are methane $\left(\mathrm{CH}_{4}\right)$, ethane $\left(\mathrm{CH}_{3} \mathrm{CH}_{3}\right)$, propane $\left(\mathrm{CH}_{3} \mathrm{CH}_{2} \mathrm{CH}_{3}\right)$, and n-butane $\left(\mathrm{CH}_{3} \mathrm{CH}_{2} \mathrm{CH}_{2} \mathrm{CH}_{3}\right)$.

amorphous - a noncrystalline liquid or solid having no well-defined melting point or molecular lattice structure. Amorphous polymers are glassy below and liquid or elastomer above the glass transition temperature.

analyte - a target compound that is physically separated from others in a sample or is interrogated separately to determine its identify or quantity.

$\mathrm{C}_{\mathrm{f}}$ - the concentration of analyte in the fiber coating.

$C_{h}$ - the concentration of analyte in the headspace.

CSA - canned subassemblies.

CW or carbowax - a polyethylene glycol (see PEG) or methoxypolyethylene glycol polymer (i.e., $\left.\mathrm{H}\left(\mathrm{OCH}_{2} \mathrm{CH}_{2}\right)_{\mathbf{x}} \mathrm{OH}\right)$ available at different approximate molecular weights.

Carboxen - a solid-phase adsorbent carbon molecular sieve used primarily for the collection of $\mathrm{C} 5$ and smaller molecules. This material comes in a variety of surface areas from 500 to $<1200 \mathrm{~m}^{2} / \mathrm{g}$. Its form is 1 - to $5-\mu \mathrm{m}$ spheres.

crystalline - a liquid or solid having a well-defined melting point or molecular lattice structure, which is characteristic of solid stage. Most commercial crystalline polymers are actually semicrystalline and are generally composed of crystallites dispersed in an amorphous phase.

$D_{f}-$ diffusion coefficient of the fiber coating.

2,4-DNT-2,4-dinitrotoluene:

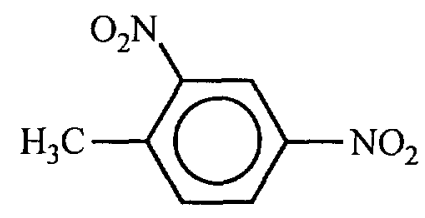

DVB - divinylbenzene. The polymer typically consists of $0-, \mathrm{m}-$, $\mathrm{p}$-isomers and ethylvinylbenzene and diethylbenzene.

$\mathbf{F}_{\mathbf{c}}$ - the column flow measured with a flow meter.

free volume - vacant spaces between polymer segments through which a chemical can penetrate into the polymer. These spaces are formed and can even migrate as the polymer chains and functional groups move, typically when the material is heated.

GC or gas chromatography - an analytical technique for vapor phase separation of different compounds in a mixture achieved by passing the mixture through a chromatographic column. The column contains an adsorbent stationary phase that retains each compound according to its interaction with the adsorbent. The different compounds emerge from the column separately and can be detected and identified by a variety of methods.

gas standard generator - an analytical instrument used for the calibration of high-sensitivity gas analyzers. In these instruments, molecular permeation of vapors through a polymeric membrane is used to establish a very small but stable and reproducible flow of a compound vapor that is mixed with a larger flow of dilution gas. These systems are capable of generating a broad range of calibration gas blends of precisely known concentration from the sub-ppb to the low-percent range.

gas permeation tube - generally a low-cost, disposable diffusion source that is made from a short length of sealed Teflon tubing filled with a com- 
pound. Vapors flow continuously through the tube walls at a rate determined by the length of the tube, wall thickness, and temperature.

glass transition temperature or $\mathbf{T}_{\mathbf{g}}$ - the temperature at which an amorphous material such as a polymer changes from a brittle vitreous state to a plastic state.

headspace - refers to the space intentionally left unoccupied in a sealed volume.

$\mathbf{K}_{\mathbf{f h}}$ - a distribution constant equal to the ratio of the analyte concentration found in the fiber coating $\left(C_{f}\right)$ to the analyte concentration in the headspace $\left(C_{h}\right)$.

LX-17 - the LLNL plastic explosive formulation consisting of $92.5 \mathrm{wt} \%$ TATB and $7.5 \mathrm{wt} \%$ Kel-F 800 (a copolymer binder of 3:1 chlorotrifluoroethylene/vinylidine fluoride)

MS or mass spectrometry - an analytical technique that provides molecular weight and structural information by gas phase separation (i.e., temporal or spatial) of compounds according to their massto-charge ratio. For analysis, compounds must be placed into the gas phase and ionized. In this work, we are using only electron impact ionization at approximately $70 \mathrm{eV}$.

$\mathbf{m} / \mathbf{z}$ - mass spectrometer unit of measure for an ionized molecule or atom. Described as ratio of atomic mass to charge. In low-energy electron impact ionization, organic molecules and their fragments only take one positive charge.

NESS - nuclear explosives safety study.

$\mathbf{p}_{\mathbf{i}}$ - the GC inlet pressure.

$\mathbf{p}_{\mathbf{m}}$ - the flow meter pressure.

$\mathbf{P}_{\mathbf{0}}$ - the column outlet pressure.

$\mathbf{p}_{\mathbf{w}}$ - the pressure of saturated water vapor.

PA or polyacrylate - a polymer family that includes the polymerization of acrylic acid, methacrylic acid, esters of these acids, or acrylonitrile. $\mathrm{R}_{1}=\mathrm{H}, \mathrm{CH}_{3}$, etc. and

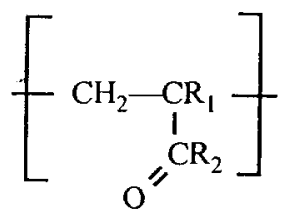
$\mathrm{R}_{2}=\mathrm{NH}_{2}, \mathrm{OCH}_{3}$, etc.:
PCS or production core sample - an assembly of primary weapon materials and components designed to replicate as accurately as possible the chemical environment and materials interfaces in a nuclear device for aging and compatibility assessment.

PDMS or polydimethylsiloxane - a silicone polymer that is highly resistant to oxidation:<smiles>[Y]C(CC)(O[Si](C)(C)C)[Si](C)(C)OC(C)(CC)[Si](C)(C)C</smiles>

PEG or polyethylene glycol - a polymer of ethylene glycol having the general formula: $\mathrm{H}\left(\mathrm{OCH}_{2} \mathrm{CH}_{2}\right)_{n} \mathrm{OH}$

$\mathbf{p p b}$ - parts per billion (typically volume/volume in gas phase collection and analysis)

ppm - parts per million (typically volume/volume in gas phase collection and analysis).

ppt - parts per trillion (typically volume/volume in gas phase collection and analysis).

polysulfide - a polymer from the reaction of sodium polysulfide with organic dichlorides such as dichlorodiethyl formed alone or mixed with ethylene dichlorides:

$$
-\left(\mathrm{SSCH}_{2} \mathrm{CH}_{2} \mathrm{OCH}_{2} \mathrm{OCH}_{2} \mathrm{CH}_{2} \mathrm{SS}\right)-
$$

RH or relative humidity - the percentage relation between the actual amount of water vapor in a given volume of air at a definite temperature and the maximum amount of water vapor that would be present if the air were saturated with water vapor at that temperature.

RSD - relative standard deviation.

SIM or single ion monitoring - mass spectrometric analysis approach whereby the mass spectrometer is tuned to a specific $\mathrm{m} / \mathrm{z}$.

SLT or stockpile laboratory test - periodic test and inspection of weapons and materials that have experienced stockpile handling and storage environments.

silica gel - porous silica beads obtained by the acid precipitation of silicate solution. Pore size typically 
ranges from 150 to $300 \AA$. This material is highly polar and will preferentially adsorb water more strongly than organic gases. Caution must be exercised when sampling high relative-humidity streams.

silicone - a siloxane polymer based on a structure consisting of alternate silicone and oxygen atoms with various organic radicals attached to the silicon:

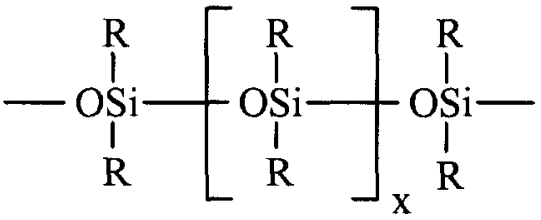

sorbent - a substance that has a great capacity for absorbing a gas or liquid.

spinodal decomposition - a phase separation of a material mixture that occurs with temperature or pressure changes and does not require activation.

$\mathbf{t}_{\mathbf{A}}$ - retention time of an unretained compound.

$\mathbf{T}_{\mathbf{e}}-$ column temperature.

$T_{g}$ or glass transition temperature - the temperature at which an amorphous material such as a polymer changes from a brittle vitreous state to a plastic state.

$T_{i}$ - the procedural decomposition temperature where specific conditions (e.g., temperature ramp rate, temperature range, bath gas, etc.) are used in the TGA of a substance as it is thermally decomposed.

$\mathbf{T m}-$ flow meter temperature.

$\mathbf{t}_{\mathbf{R}}-$ compound $\mathrm{GC}$ retention time.

TATB - 1,3,5-triamino-2,4,6-trinitrobenzene:<smiles>Nc1c(N)c([N+](=O)[O-])c(N)c([N+](=O)[O-])c1N</smiles>

TGA or thermogravimetic analysis - an analytical technique that involves recording the weight of a substance over time as the system is controllably heated or cooled.

TNT - 2,4,6-trinitrotoluene:<smiles>Cc1c([N+](=O)[O-])cc([N+](=O)[O-])cc1[N+](=O)[O-]</smiles>

Tenax - a solid phase sorbent that generally refers to Tenax TA, which is a polymer of 2,6-diphenyl-pphenylene oxide.

toluene - methylbenzene:

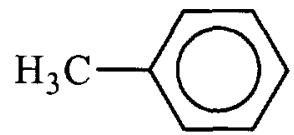

\section{1,3,5-trichloro-2,4,6-trinitrobenzene - a synthesis} intermediate of TATB:<smiles>O=[N+]([O-])c1c(Cl)c(Cl)c([N+](=O)[O-])c([N+](=O)[O-])c1Cl</smiles>

$\mathbf{v} / \mathbf{v}$ - volume/volume.

volatiles or volatile organic compounds - any hydrocarbon, except methane and ethane, with a vapor pressure equal to or greater than 0.1 torr.

$x_{0}-$ the thickness of the polymer coating. 


\section{References}

1. M. Frances Foltz and James D. LeMay, Trip Report: Disassembly of W84/W87 PCS S/N 45C, Lawrence Livermore National Laboratory, Livermore, CA, (January 23, 1996).

2. Zhang, Z.; Yang, M.J.; Pawliszyn Anal. Chem. 1994, 66, 844A-853A.

3. Berezkin, V.G. Gas Chromatography in Air Pollution Analysis; Elsevier: New York, 1991.

4. Almasi, E.; Kirshen, N.; Kern, H. Int. J. Environ. Anal. Chem. 1993, 52, 39-48.

5. ' Davoli, E.; Cappellini, L.; Moggi, M.; Fanelli, R. J. Am. Soc. Mass Spectrom. 1994, 5, 1001-1007.

6. McCaffrey, C.A.; Maclachlan, J.; Brookes, B.I. Analyst, 1994, 119, 897-902.

7. Bianchi, A.P.; Varney, M.S. J. Chromatogr. 1993, 643, 11-23.

8. Oliver, K.D.; Adams, J.R.; Daughtrey, E.H.; McClenny, W.A.; Young, M.I.; Pardee, M.A.; Almasi, E.B.; Kirshen, N.A. Environ Sci. Technol. 1996, 30, 1939-1945.

9. LaPack, M.A.; Tou, J.C.; Enke, C.G. Anal. Chem. 1990, 62, 1265-1271.

10. Cisper, M.E.; Gill, C.G.; Townsend, L.E.; Hemberger, P.H. Anal. Chem. 1995, 67, 1413-1417.

11. McLuckey, S.A.; Glish, G.L.; Asano, K.G. Anal. Chim. Acta 1989, 225, 25-35.

12. Ketkar, S.N.; Dulak, J.G.; Dheandhanoo, S.; Fite, W.L. Anal. Chim. Acta 1991, 245, 267-270.

13. Kelly, T.J.; Kenny, D.V. Atmospheric Environment, 1991, 25A, 2155-2160.

14. Wise, M.B.; Thompson, C.V.; Buchanan, M.V.; Merriweather, R.; Guerin, M. Spectroscopy 1993, 8, 14-22.

15. Hart, K.J.; Dindal, A.B.; Smith, R.R. Rapid Commun. Mass Spectrom. 1996, 10, 352-360.

16. Gordon, S.M.; Callahan, P.J.; Kenny, D.V. Rapid Commun. Mass Spectrom. 1996, 10, 1038-1046.

17. Chambers, D.M.; Grace, L.I; Andresen, B.D. Anal. Chem. 1997, 69, 3780-3790.

18. Pawliszyn, J. Solid Phase Microextraction Theory and Practice, Wiley, New York, 1997, p. 111.

19. Langenfeld, J.J.; Hawthorne, S.B.; Miller, D.J. J. Chromatogr. A, 1996, 740, 139-145.

20. Eisert, R; Pawliszyn, J. J. Chromatogr. A 1997, 776, 293-303.

21. Poerschmann, J; Zhang, ZY; Kopinke, FD; Pawliszyn, J. Anal. Chem., 1997, 69, 597-600.

22. Page, B.D.; Lacroix, G. J. Chromatogr. A, 1997, 757, 173-182.

23. Pawliszyn, J. Solid Phase Microextraction Theory and Practice, Wiley, New York, 1997, p. 51.

24. Pawliszyn, J. Solid Phase Microextraction Theory and Practice, Wiley, New York, 1997, p. 144. 
25. Kirkbride, K.P.; Klass, G.; Pigou, P.E., J. Forensic Sci. 1998, 43, 76

26. Chan, Yoon-Jong; Choe, Soonja J. Appl. Polym. Sci., 1995, 58(1), 147-57.

27. Zhang, Z.; Pawliszyn, J. J. Phys. Chem. 1996, 100, 17648.

28. Pawliszyn, J. J. Anal. Chem. 1992, 64, 1552.

29. Ioffe, B.V.; Vitenberg, A.G. Head-Space Analysis and Related Methods in Gas Chromatography; Wiley \& Sons: New York, 1984; p. 143. 
Solid Phase Microextracrion for the Analysis of Nuclear Weapons 